\title{
Adolescent reproduction: the case of Chile and its policy implications
}

\author{
Jorge Rodriguez $V$.
}

1

dolescent fertility and maternity are a source of concern in the Latin American and Caribbean region, because they imply situations of adversity, have not gone down as in other age groups, and are more frequent among poor teenagers. Analysis of the micro-data from the last three censuses in Chile also shows: i) a generalized tendency for adolescent maternity to be out of wedlock; ii) the protective effect of staying in school, which comes into play after passing an educational threshold which is rising with time; iii) the leading role played by the parents of the households where most adolescent mothers live, and iv) the need for specific programmes and integral actions to reduce adolescent maternity, since although access to information and sexual health and reproduction services avoids pregnancies, it is not enough when there is a lack of alternatives to maternity or there are cultural and psychological obstacles to the proper use of contraceptive methods. 


\section{I}

\section{Introduction}

Recent studies (Rodríguez, 2004; Flórez and Nuñez, 2003; ECLAC/CELADE, 2002) and data from specialized surveys — such as demographic and health surveys (www.measuredhs.com) - suggest that in a number of countries of Latin America and the Caribbean adolescent fertility, that is to say, fertility before 20 years of age, has risen over the last two decades, thus contrasting with the fertility of other age groups and total fertility, which have been going down steadily and markedly (table 1). When in addition it is considered that adolescent fertility generates situations of adversity, at least for the parents and their offspring (eCLAC/ois, 2004 and 2003; eCLAC/CELAde, 2002 and 2004; Flórez and Núñez, 2003; Menkes and Suárez, 2003; Molina, Sandoval and González, 2003; Silber and Castells, 2003; IPAs, 2001; Lete, de Pablo and others, 2001; Gage, 1995), it may be concluded that this is a matter that calls for specific, systematic and urgent analysis and action.

In order to take action with regard to this fertility, a detailed and up-to-date knowledge is required of its nature, its determinants, and above all, those who are affected by it. It is urgently necessary to obtain this knowledge, because recent studies on this subject have shown that part of present-day adolescent reproduction no longer conforms to the model which prevailed up to a few decades ago (ECLAC/oIJ, 2004). Up to the 1970 s, the countries with high rates of adolescent fertility also tended to have high levels of total fertility. Likewise, women who started their reproductive period early -i.e., who began as adolescent mothers - tended to have a large number of children by the end of that period. This forms part of a syndrome which we could call "traditional reproductive behaviour", which still persists in poor countries and among indigenous populations. It usually involves early initiation of nuptiality and low levels of contraceptive use.

The pattern which has emerged since the mid1980s in addition to this traditional pattern could be called a pattern of truncated reproductive (or sexual) modernity, ${ }^{1}$ because a moderate final parity (two to

\footnotetext{
1 The use of the word "modernity" does not have any ethical connotations, nor does it imply a positive appraisal. It is simply used because in modern (industrialized, developed) societies,
}

three children, thanks to deliberate birth control) begins with early maternity. These persons are girls who have their first child during adolescence but are subsequently more motivated to control their fertility or, by the fact of being mothers, have easier access to family planning programmes, thus enabling them to fulfil their desire to have only a small number of children.

Table 2 shows this growing process of delinking between the initiation and intensity of fertility at the aggregate level, using for this purpose simple correlation between the age-specific fertility rates and the total fertility rate of the countries concerned. Since the latter rate is the sum of the former, a high degree of correlation might be expected. At the world level, this correlation is observed for all ages except the 1519 age group, which is "delinked", and this delinking is most noticeable in the case of Latin America and the Caribbean. This is because countries with low total fertility register moderate (Brazil, Colombia) or high (Dominican Republic) levels of adolescent fertility, while countries with high total fertility (Haiti and Bolivia) register relatively low or moderate levels of adolescent fertility. Even so, countries with high adolescent fertility tend to have higher levels of total fertility (Guatemala, Nicaragua, Honduras).

It has also been noted that the current pattern of adolescent reproduction differs from the earlier pattern because it is more likely to take place outside a stable union; for this reason, it usually has intergenerational implications too, because the family of an adolescent mother is seen as the obvious source of support when an ongoing relationship between the mother and her partner is weak or non-existent (ECLAC/OIJ, 2004).

In view of the regional details, the conceptual discussions and the practical necessities described above, this study seeks to contribute updated knowledge and information in order to permit a better understanding of adolescent reproduction, its tendencies, and some of its connotations for girls and

recognition of the capacity of persons and couples to control their fertility is widely established and methods are available for exercising that control, so that sexuality can be effectively separated from reproduction. In those societies (especially in Western Europe and Japan), it is also systematically observed that the decline in fertility is accompanied by later initiation of reproduction. 
TABLE 1

Latin America (eight countries): Evolution of age-specific fertility rates (per thousand), by five-year age groups, and total fertility rates in the years indicated

\begin{tabular}{|c|c|c|c|c|c|c|c|c|}
\hline \multirow[t]{2}{*}{ Country and year } & \multicolumn{7}{|c|}{ Age groups } & \multirow{2}{*}{$\begin{array}{c}\text { Total fertility } \\
\text { rate }\end{array}$} \\
\hline & $15-19$ & $20-24$ & $25-29$ & $30-34$ & $35-39$ & $40-44$ & $45-49$ & \\
\hline Bolivia, 1989 & 98.5 & 234.5 & 245.1 & 198.7 & 141.5 & 67.4 & 21.6 & 5.0 \\
\hline Bolivia. 2003 & 84.0 & 183.0 & 179.0 & 145.0 & 114.0 & 51.0 & 12.0 & 3.8 \\
\hline Brazil. 1986 & 74.2 & 186.1 & 169.4 & 128.0 & 80.2 & 36.8 & - & 3.4 \\
\hline Brazil 1996 & 86.3 & 152.3 & 122.7 & 80.9 & 46.5 & 15.6 & 2.9 & 2.5 \\
\hline Colombia. 1986 & 73.4 & 176.8 & 159.9 & 118.0 & 77.1 & 28.0 & 7.5 & 3.2 \\
\hline Colombia. 2000 & 84.8 & 142.0 & 129.3 & 98.9 & 48.9 & 15.4 & 2.2 & 2.6 \\
\hline Guatemala. 1995 & 133.8 & 267.6 & 262.7 & 206.3 & 148.0 & 81.8 & - & 5.5 \\
\hline Guatemala. 2002 & 114.0 & 233.0 & 218.0 & 150.0 & 119.0 & 38.0 & 4.0 & 4.4 \\
\hline Haiti. 1994/95 & 75.7 & 178.7 & 233.0 & 205.7 & 165.6 & 78.0 & 19.1 & 4.8 \\
\hline Haiti. 2000 & 86.3 & 182.8 & 198.1 & 219.0 & 161.2 & 74.1 & 17.2 & 4.7 \\
\hline Peru 1986 & 78.9 & 183.9 & 198.7 & 161.3 & 122.2 & 63.7 & 14.4 & 4.1 \\
\hline Peru 2000 & 66.2 & 139.7 & 134.4 & 112.2 & 79.0 & 32.0 & 6.1 & 2.8 \\
\hline Nicaragua. 1997/98 & 130.1 & 192.3 & 161.8 & 122.2 & 78.4 & 32.2 & 9.5 & 3.6 \\
\hline Nicaragua 2001 & 119.0 & 178.0 & 145.0 & 108.0 & 64.0 & 26.0 & 6.0 & 3.2 \\
\hline Dominican Republic. 1986 & 99.7 & 202.4 & 195.3 & 127.0 & 70.9 & 32.4 & 8.4 & 3.7 \\
\hline Dominican Republic. 2002 & 116.0 & 190.0 & 145.0 & 97.0 & 41.0 & 8.0 & 1.0 & 3.0 \\
\hline
\end{tabular}

Source: www.measuredhs.com (on-line processing with STAT compiler and on-line country reports in the cases of Bolivia, 2003; Guatemala, 2002; Nicaragua, 2001, and Dominican Republic, 2002).

TABLE 2

World total and Latin America and the Caribbean: Simple correlations between specific fertility rates and total fertility rates, by countries, 1995-2000

(World total and two samples of Latin America and the Caribbean)

\begin{tabular}{|c|c|c|c|}
\hline Specific rate for age group & World total $^{\mathrm{a}}$ & Latin America and the Caribbean ${ }^{b}$ & Latin America and the Caribbean ${ }^{\mathrm{c}}$ \\
\hline $15-19$ & 0.700 & 0.330 & 0.480 \\
\hline $20-24$ & 0.837 & 0.837 & 0.960 \\
\hline $25-29$ & 0.959 & 0.980 & 0.992 \\
\hline $30-34$ & 0.953 & 0.928 & 0.952 \\
\hline $15-19$ & 0.700 & 0.330 & 0.480 \\
\hline $35-39$ & 0.934 & 0.900 & 0.892 \\
\hline $45-49$ & 0.863 & 0.688 & 0.571 \\
\hline
\end{tabular}

Source: Calculations based on data obtained from www.measuredhs.com.

a 51 countries, including 8 from Latin America and the Caribbean, with data from surveys carried out after 1995.

b Bolivia, 1998; Brazil, 1996; Colombia, 2000; Guatemala, 1998/99; Haiti, 2000; Nicaragua, 1997/98; Peru, 2000; Dominican Republic, 2002.

c Excluding Haiti.

their families in Chile. That country was chosen because there are few recent socio-demographic studies on this matter, this issue is one of the items on the public agenda, and the availability of micro-data from three censuses carried out over a period of 20 years provides an exceptional opportunity in terms of the availability of information. A first objective, then, is to determine if Chile is one of the countries of the region in which adolescent reproduction is increasing, in contrast with what is happening in the other age groups. In addition, this study will seek to appraise the hypotheses on emerging forms of adolescent reproduction, since because of Chile's advanced position in the demographic transition and the fact that 
its socio-economic indices are well above the regional average, it is extremely unlikely that this reproduction is due to traditional patterns. Although this study deals with specific fertility rates, the novelty of its contribution lies in its analysis of adolescent maternity, ${ }^{2}$ for the identification of mothers under 20 years of age makes it possible to calculate indicators of adolescent reproductive patterns and to gain a clear picture of those mothers and their households, thus providing inputs for policy design and shedding light on the nature and determinants of this type of behaviour.

\section{II}

\section{Adolescent fertility and maternity in Chile: their evolution over the last $\mathbf{4 0}$ years}

There are no recent fertility surveys for Chile. There are three surveys on adolescents and young people (www. inj.cl), but their modules on sexual, nuptial and reproductive behaviour are insufficient and have been very little used; there is also a survey on sexual behaviour carried out by the National Commission on AIDS (CONASIDA, 2000) and a couple of health surveys carried out recently by the National Statistical Institute (INE) and the Ministry of Health, but their circulation has been limited and they have been little used so far. Chile does have good-quality vital statistics and census micro-data bases in REDATAM ${ }^{3}$ format (for 1982, 1992

\footnotetext{
${ }^{2}$ In demography, the concept of fertility refers to the number of children women have during their reproductive period and can be calculated as the average number of children of a real cohort (mean parity, or final parity if the cohort has finished its reproductive life) or the sum of the age-specific fertility rates (total fertility rate, whose interpretation requires some assumptions). Maternity, in contrast, places women in one of two mutually exclusive categories: mothers and childless (nulliparous females). Although demographers usually concentrate on fertility, for operational and policy reasons adolescen maternity has been taking on growing importance and visibility. On the operational level, since this takes place at the beginning of the reproductive period, the percentage of mothers among females under 20 years of age is closely linked with the fertility at that age; obviously, this association tends to weaken with age, since relatively universal maternity may be registered in countries of high or low total fertility (in the latter case, if all women have a single child in their life). At the policy level, at that age the important thing is no so much the average number of children as the distinction between whether or not girls have had children or not. In the present study, the expression "adolescent fertility" will be used both to refer generically to biological reproduction before the age of 20 and to refer specifically to the intensity of reproduction during that period, whether in terms of specific rates or the average number of children. The term "adolescent maternity", for its part, will be used to refer generically to the fact of becoming a mother before the age of 20 and specifically, to the proportion of mothers among adolescents. 3 REDATAM: The software developed by CELADE for data recovery for small areas by micro-computer.
}

and 2002), however, and using these latter two sources provides irrefutable evidence on the reluctance of adolescent fertility to go down (figures 1 and 2), since the only specific fertility rate which did not go down sharply between 1960 and 2001 was the rate for the 15-19 age group, which has tended to remain constant, with some fluctuations; thus, its level in 2001 was $90 \%$ of that registered in 1960, whereas over the same period total fertility and the fertility of all the other age groups went down by at least $50 \%$.

Census data have traditionally been used for indirect estimates of fertility, using procedures developed by demographers (United Nations, 1983) which make use of the questions on the total number of children born alive and the number of children born in the last year (captured in some censuses through the question on the date of birth of the youngest child). In the past, those estimates have been made on the basis of the published data, and experience suggests that they tend to underestimate adolescent fertility because of the very frequent failure of girls under 20 to give an answer to those questions. Nevertheless, the development of procedures to correct this problem using aggregate data has made it possible to arrive at relatively reliable estimates. Calculations made using the $\mathrm{P} / \mathrm{F}$ method $^{4}$ proposed by Brass (United Nations, 1983) — applied by using a special REDATAM module which includes some data treatment and screening criteria - suggest that the specific adolescent fertility rate (15-19 age

\footnotetext{
4 The P/F procedure developed by Brass is so named because its estimates are based on the quotient between the cumulative parity (P), obtained from the question on the number of children born alive, and the spot or current fertility (F), calculated on the basis of the question on the children born alive in the last year. The procedure thus provides adjusted specific and total fertility rates.
} 
FIGURE 1

Chile: Specific and total fertility rates, 1960-2000

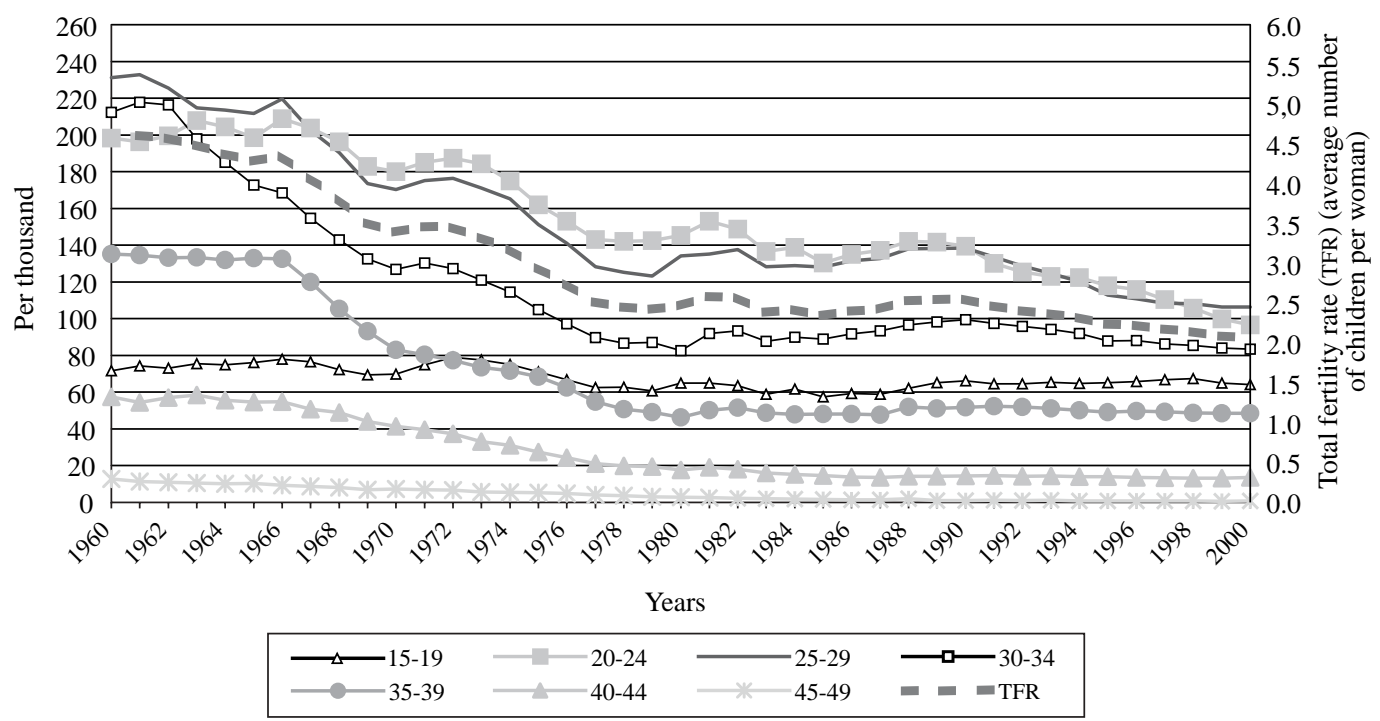

Source: Calculated on the basis of vital statistics taken from the Anuario de Demografía of the National Statistical Institute (INE, various years). In order to correct problems of timeliness, the data from the most up-to-date edition were used.

FIGURE 2

Chile: Specific and total fertility rates, $1960-2000$

$(1960=100)$

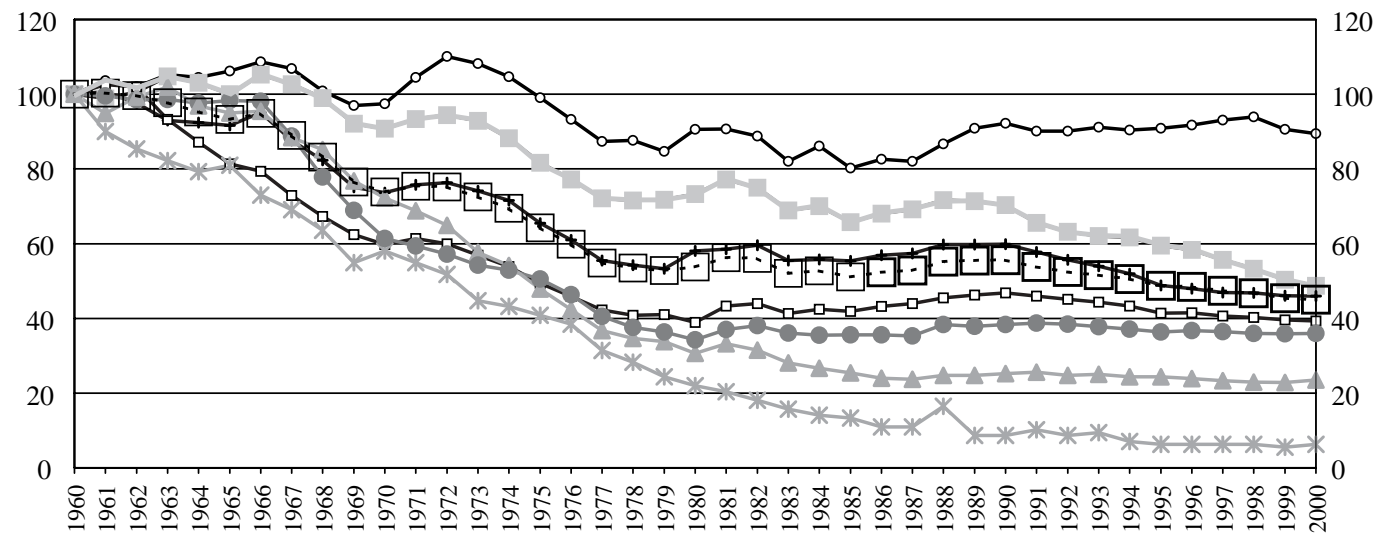

\begin{tabular}{|c|c|c|c|}
\hline$\longrightarrow-15-19$ & $-20-24$ & $\longrightarrow$ 25-29 & $\longrightarrow$ —-30-34 \\
\hline$-35-39$ & $\longrightarrow-40-44$ & - $45-49$ & -- $\square---T F R$ \\
\hline
\end{tabular}

Source: Calculated on the basis of vital statistics taken from the Anuario de Demografia of the National Statistical Institute (INE, various years). In order to correct problems of timeliness, the data from the most up-to-date edition were used.

group) has remained almost unchanged, at between 65 and 70 per thousand, over the 1982-2002 period (results available from the author on request).

The published census data have also been used to estimate the absolute and relative numbers of adolescent mothers. Thus, it may be seen from table 3, using the published data from the question about the number of children born alive contained in the Chilean censuses of 1982, 1992 and 2002, that adolescent maternity has increased slightly in the last two decades. 
TABLE 3

Chile, women between 15 and 19 years of age: Absolute and relative figures on their distribution according to maternity status, 1982, 1992 and 2002

(Numbers and percentages)

\begin{tabular}{lccc}
\hline No children & Children & $\begin{array}{l}\text { Don't know/ } \\
\text { don't answer }\end{array}$ & Total \\
\hline $\begin{array}{l}1982 \\
429402\end{array}$ & 71541 & 151609 & 652552 \\
65.80 & 10.96 & 23.23 & 100.00 \\
1992 & & & \\
414158 & 69890 & 116515 & 600563 \\
68.96 & 11.64 & 19.40 & 100.00 \\
2002 & & & \\
426580 & 77291 & 124505 & 628376 \\
67.89 & 12.30 & 19.81 & 100.00 \\
& & &
\end{tabular}

Source: Official publications of national population censuses.

This table also shows the high frequency of failure to answer the question on children born alive. The experience acquired in investigating this topic suggests, however, that the great majority of girls who do not answer are in fact childless (Rodríguez, 2004), and that in the absence of additional information or reliable adjustment procedures they can safely be considered as such: the error in measurement that might be committed in this way would be much smaller than if the proportion of adolescent mothers were calculated solely on the basis of the women who answered this question, for if we proceeded in the latter manner, the level of adolescent maternity in Chile would rise to $15.34 \%$ in 2002.5

Table 3 shows how adolescent maternity was investigated before there was easy access to census micro-data bases. This access is now possible, and allows us to begin to find answers to many questions on adolescent fertility. Likewise, some of the problems of measuring this phenomenon can now be tackled using new procedures. Tables 4 and 5 are the result of special processing of census micro-data bases, using REDATAM, which has enabled us to progress on two matters of crucial importance: i) empirically testing the hypothesis on the increasingly early initiation of adolescent maternity (INE, 2000), and ii) evaluating the tendency according to the simple age of adolescent

\footnotetext{
5 Table 3: $\left(\frac{77291}{628376-124505}\right) * 100$.
}

maternity, imputing the status of mothers to girls who do not provide information in this respect, and correcting "unacceptable" answers. ${ }^{6}$ Table 4 -which, as it estimates the percentage of mothers for the total number of women, would be correct if those for whom there was no information were nulliparous (a hypothesis which would appear to be correct for the great majority of girls, but not all) - confirms the aggregate data showing that there has been an increase in adolescent maternity for the entire 15-19 age group and that this increase was most marked in the case of the youngest girls, especially in the 1992-2002 period, a particularly striking feature being the significant increase in the number of girls who were mothers at the age of $15 .{ }^{7}$ An even more striking feature is that table 4 makes it possible to conclude that there was an increase in the probability of being a mother for all ages except the oldest (19), which undoubtedly supports the disturbing hypotheses that adolescent maternity is taking place at an increasingly early age. These results coincide with those presented by the INE (2000), although the indicator used in the latter publication was the specific fertility rate by simple age and the data came from vital statistics for the 19801998 period (INE, 2000, p. 3).

Table 5 shows calculations using the imputation procedure referred to above. The results slightly modify the picture given in table 4 , since although they confirm an increase in adolescent maternity between 1982 and 2002 , especially at the younger ages, in the period from 1992 to 2002 they show a situation of stability in which only the substantial rise in the level of maternity of girls aged 15 stands out (although the information on that age group suffers from problems in 2002, as already noted). These results must naturally be viewed in the light of the criteria used to obtain them, but they do

\footnotetext{
${ }^{6}$ A value of 1 or 0 was imputed to adolescents who did not answer this question when enumerated, using a simple algorithm whereby: i) if a girl was single, she was classified as having 0 children; ii) if she was married, cohabiting, separated or annulled she was classified as having 1 child. In addition, because of the errors displayed by the census, maximum values were fixed for the number of children that an adolescent could biologically have. The results were thus re-coded as follows: i) adolescents between 15 and 17 can declare a maximum of three children; ii) adolescents between 18 and 19 can declare a maximum of four children.

${ }^{7}$ This proportion was $6.3 \%$ in 2002 , that is to say, three times the percentage registered in 1992. These figures will be reviewed later in the light of additional information, because they would appear to be affected by systematic errors in measurement which could possibly explain the large size of the increase (but not the upward tendency itself).
} 
Chile, women between 15 and 19 years of age: Absolute and relative figures (without correction or imputation) on maternity status, by simple age, 1982,1992 and $2002^{\mathrm{a}}$

\begin{tabular}{|c|c|c|c|c|c|c|c|c|c|c|c|c|}
\hline \multirow[t]{2}{*}{ Age } & \multicolumn{4}{|c|}{1982} & \multicolumn{4}{|c|}{1992} & \multicolumn{4}{|c|}{2002} \\
\hline & Total & Mothers & $\begin{array}{l}\text { Don't know/ } \\
\text { don't answer }\end{array}$ & $\%$ of mothers & Total & Mothers & $\begin{array}{l}\text { Don't know/ } \\
\text { don't answer }\end{array}$ & $\%$ of mothers & Total & Mothers & $\begin{array}{l}\text { Don't know/ } \\
\text { don't answer }\end{array}$ & $\%$ of mothers \\
\hline 15 & 132898 & 2077 & 40744 & 1.56 & 112098 & 2317 & 25553 & 2.07 & 140646 & 8902 & 34764 & 6.33 \\
\hline 16 & 128085 & 5315 & 30866 & 4.15 & 116439 & 5609 & 24499 & 4.82 & 123619 & 6327 & 26870 & 5.12 \\
\hline 17 & 131254 & 11686 & 27952 & 8.90 & 122678 & 12078 & 23828 & 9.85 & 120195 & 12204 & 23946 & 10.15 \\
\hline 18 & 131725 & 20555 & 24308 & 15.60 & 127211 & 20443 & 23356 & 16.07 & 120763 & 20198 & 20368 & 16.73 \\
\hline 19 & 128590 & 31908 & 20303 & 24.81 & 122137 & 30288 & 18434 & 24.80 & 123153 & 29660 & 18557 & 24.08 \\
\hline Total & 652552 & 71541 & 144173 & 10.96 & 600563 & 70735 & 115670 & 11.78 & 628376 & 77291 & 124505 & 12.30 \\
\hline
\end{tabular}

Source: Special processing of census micro-data bases.

a The processing of micro-data gives data that do not coincide exactly with the data published by the INE in 1992 and 1982 (table 3 ). When the reasons for this discrepancy were investigated, it was found that in 1992 the INE placed all the answers "considered to be anomalous because they were too high" in the "don't know/don't answer" category: i.e., 15 years old with more than three children, 16 years old with more than four children, 17 years old with more than five children, 18 years old with more than six children, and 19 years old with more than seven children. In table 4 these cases (of which there were only a few in 1992) are included under the "mothers" category, because their marital and educational status is much more similar to that of girls with children: in other words, they gave inaccurate answers, but almost certainly had children. As regards the difference with 1982, this is because the INE publication used the filter question as to whether they had had children or not to identify "undeclared fertility", rather than the direct question about the number of children born alive which was used to obtain the data in table 4. Furthermore, a small number of cases (precisely the discrepancy between the official tabulation and the processed micro-data) where there was no answer to the filter question were classified in the "nulliparous" category in the question on the number of children born alive, without any explanation as to why this was done. At all events, the effect of this is irrelevant, since it refers to girls with "unknown fertility" and not to mothers, regarding whom the figures of the publication and the processed data coincide.

TABLE 5

Chile, women between 15 and 19 years of age: Absolute and relative figures on maternity status (with imputation of maternal status to girls who did not answer or gave anomalous answers), by simple age, 1982, 1992 and 2002

\begin{tabular}{|c|c|c|c|c|c|c|c|c|c|}
\hline \multirow[t]{2}{*}{ Age } & \multicolumn{3}{|c|}{1982} & \multicolumn{3}{|c|}{1992} & \multicolumn{3}{|c|}{2002} \\
\hline & Total & Mothers & $\%$ of mothers & Total & Mothers & $\%$ of mothers & Total & Mothers & $\%$ of mothers \\
\hline 15 & 132898 & 3058 & 2.30 & 112098 & 5012 & 4.47 & 140646 & 11331 & 8.05 \\
\hline 16 & 128085 & 5761 & 4.50 & 116439 & 7959 & 6.84 & 123619 & 7392 & 5.97 \\
\hline 17 & 131254 & 12465 & 9.50 & 122678 & 14320 & 11.67 & 120195 & 13316 & 11.07 \\
\hline 18 & 131725 & 21554 & 16.36 & 127211 & 23332 & 18.34 & 120763 & 21472 & 17.78 \\
\hline 19 & 128590 & 33322 & 25.91 & 122137 & 32636 & 26.73 & 123153 & 31271 & 25.39 \\
\hline Total & 652552 & 76160 & 11.67 & 600563 & 83259 & 13.86 & 628376 & 84782 & 13.49 \\
\hline
\end{tabular}

Source: Special processing of census micro-data bases.

confirm the main finding that adolescent maternity increased in Chile in the last 20 years and that this increase was most marked among the younger girls. Just as important as the relative proportion of mothers among adolescent girls (of the order of $13 \%$ in the census; see tables 4 and 5) —which could lead to hasty interpretations which assign less importance to early reproduction as a public policy issue, because it only affects a minority of girls - is the value registered for the 19 age group, which is the value that comes closest to the probability of becoming a mother in adolescence. According to this figure, at least one out of every four Chilean women has been an adolescent mother in the last two decades. 


\section{III}

\section{What is the nuptial context in which adolescent mothers have their children?}

Historically, early maternity has been associated with a higher probability of occurring in an informal context (girls who are unmarried or merely cohabiting with a man) (Guzmán, Hakkert and others, 2001; Buvinic, 1998). The INE recently reconstructed fertility and maternity series by marital status of the mother which revealed that as many as $90 \%$ of 15 year old mothers are unmarried (INE, 2000, p. 4). As these figures are based on administrative records (vital statistics), however, they inflate the proportion of unmarried mothers because they do not recognize the status of common-law wife, which is taken into account in the census. In 1982 most adolescent mothers were married $;{ }^{8}$ unmarried mothers accounted for $40 \%$ of the total, but cohabitation was not frequent. In 1992, unmarried adolescent mothers were the majority among that age group, albeit only by a slight margin. By 2002, however, the change was already firmly established, since $55 \%$ of adolescent mothers declared themselves as unmarried ${ }^{9}$ and those who were cohabiting outnumbered those who were legally married; indeed, only $17 \%$ of mothers between the ages of 15 and 19 were married (figure 3 ).

Figure 4 shows the evolution of the proportion of unmarried girls, by marital status, between 1982 and 2002. At all ages (except in the anomalous case of 15 year old girls in 2002) there was an increase in the proportion of unmarried girls among

FIGURE 3

Chile, girls between 15 and 19 years of age: Relative distribution by marital and maternity status, 1982, 1992 and 2002

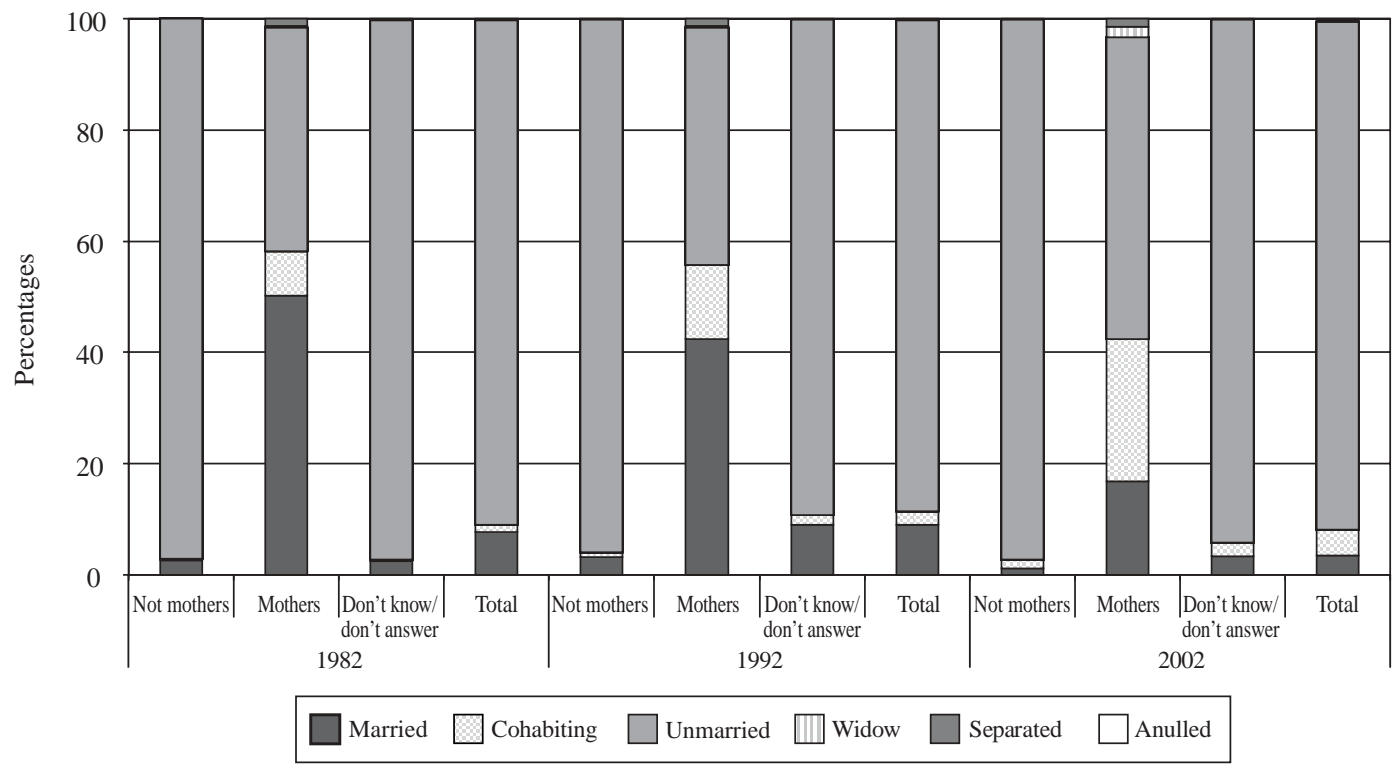

Source: Special processing of census micro-data bases.

${ }^{8}$ Although not necessarily with the child's father.

9 This declaration does not mean that they had not been married but
were no longer living with their husband at the time of the census.
They could of course have cohabited with a partner at some point in
their lives, but the census does not take this information into account. 


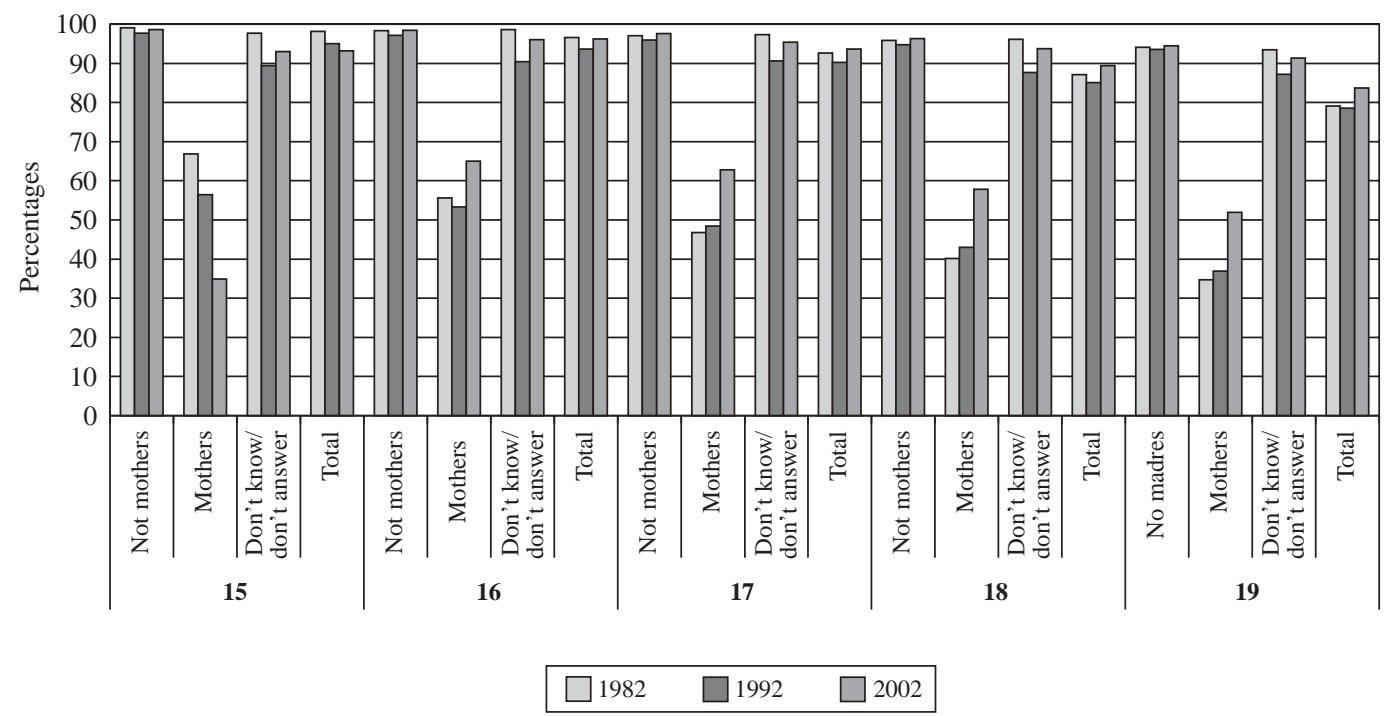

Source: Special processing of census micro-data bases.

adolescent mothers, which rules out the possibility that the evolution of the aggregate figures in figure 3 is due in some way to the age structure. It may also be noted that the earlier maternity takes place, the more likely it is that it will occur out of wedlock ${ }^{10}$ (figures 3 and 4).

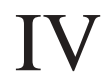

\section{Where do adolescent mothers live, and what do they do: emancipation or confinement?}

Maternity involves a change of status for adolescents. When a traditional pattern prevails, this change is associated with nuptiality or is the result of it, and it therefore leads to the formation of a new household, sometimes in a dwelling other than that of the couple's parents, and other times in the dwelling of one of them. The form of adolescent maternity which is emerging, and which was described in the previous section, however, gives rise to a whole new scenario for girls who have children. This is because the lack of a stable partner makes it hard to think that pregnancy will lead to the formation of a family and/or independence of the household of origin. For these reasons, these girls must look for support elsewhere, which, according to the classic distinction of Esping-Andersen (1999), may be: i) the family, which offers shelter and care, devotes time to looking after the child, and provides resources; ii) the State, which combats discrimination, provides schools, day nurseries and counselling services, grants benefits and defines guarantees; and iii) the market, which offers employment.

Figure 5 presents striking evidence on the support received by adolescent mothers: as might be expected, there is a differentiation between mothers and, since

10 "Out of wedlock" is not the same as absence of the father, because although for some adolescent couples maternity/paternity has nothing to do with being married or living together, this does not mean that there are no links of affection or that the couples do not see each other regularly (Buvinic, 1998, p. 5). 
FIGURE 5

Chile, girls between 15 and 19 years of age: Relative distribution of position occupied in the household, by maternity status, 1992 and 2002

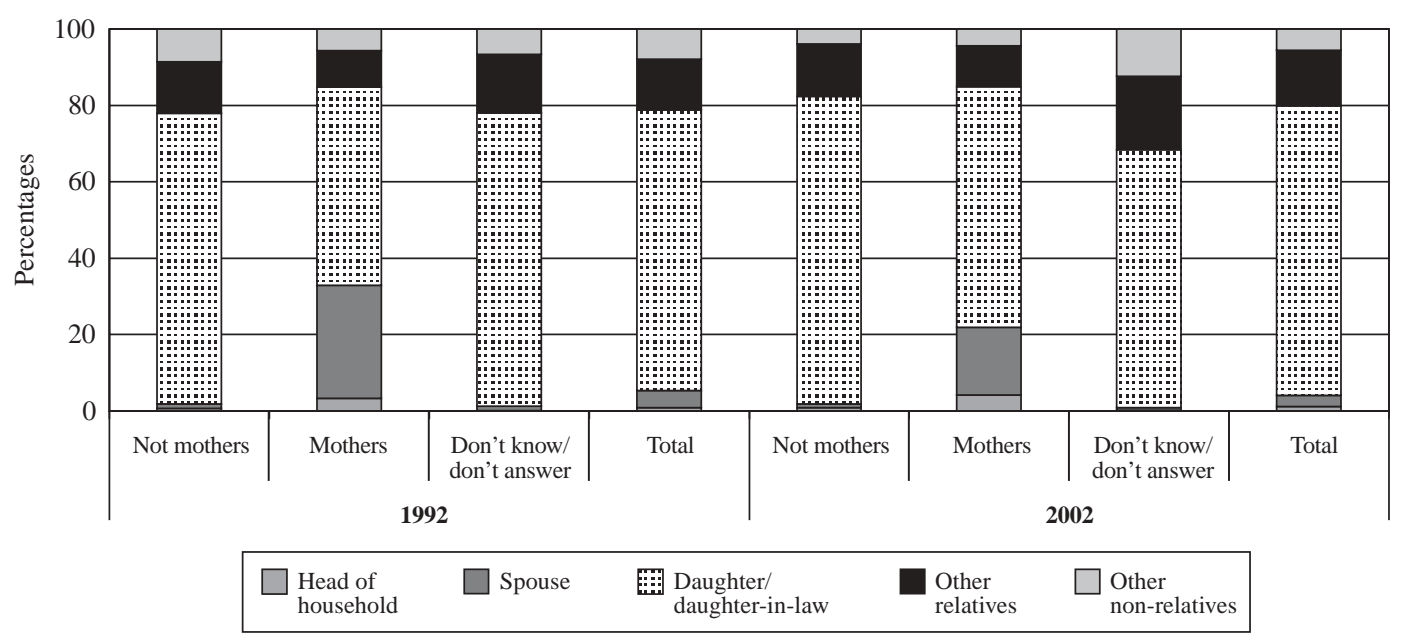

Source: Special processing of census micro-data bases.

the latter, almost without exception, live with their parents or other relatives, while a proportion of the former have formed an independent household (although not necessarily a dwelling of their own). The conclusion which emerges from those data, however, is that the family of adolescent mothers is the main source of support for bringing up their children. Thus, most of them live with their family or their partner's family, as shown by the fact that the predominant relationship to the head of household is that of daughter or daughter-in-law, and the most frequent place of residence is with the girl's family. Setting up an independent household seems difficult, since in 2002 there were more adolescent mothers living in the household of some secondary relative or non-relative (taken together) than those living in a household headed by the girl's spouse (figure 5). As might be anticipated, the earlier a girl's maternity, the more important is the role of the family of origin; even so, the majority of mothers aged 19 live with their parents or in-laws (figure 6).

The trend data (2002-1992) reveal that the role of the family as the place where adolescent mothers are taken in is increasingly important, which is connected with the already noted increase in unmarried adolescent motherhood (figures 5 and 6). In other words, the family of origin seems to fill, at least in part, the empty space left by the absence of the girl's partner. This statistical observation does not permit a more specific assessment of the effective support given by the family to adolescent mothers and their children; the census data only show that the family provides food and lodging, but do not provide information on other forms of support such as the time devoted to looking after the children, transfers of resources, affection and care. More precisely focused research - some of it qualitative rather than quantitative- is needed to determine the exact role of the family in the development of the adolescent mother and her child.

The important support given by the family, however, does not seem to be sufficient to enable the girls to reconcile their duties in bringing up their children with school attendance or employment. Figure 7 is expressive in this respect, since according to the 2002 census the probability of studying full-time goes down from $80 \%$ for girls between 15 and 19 who have not had children to only $20 \%$ for those who have. Dropping out of the school system does not make adolescent mothers more likely to participate in the labour market, however: their daily activities correspond mostly to housework, which strengthens the hypothesis that early maternity simultaneous obstructs both education and employment. The evidence therefore indicates that early reproduction is associated with dropping out of school -in a complex relationship which will be explained below- but not with entry of the girls into the labour market (ECLAC/ OIJ, 2004 and 2003; Rodríguez, 2004; SERNAM, 2004).

Examination by simple ages makes it possible to refine the analysis, because the universal educational 
FIGURE 6

Chile, girls between 15 and 19 years of age: Relative distribution of position occupied in the household, by simple age and maternity status, 1992 and 2002

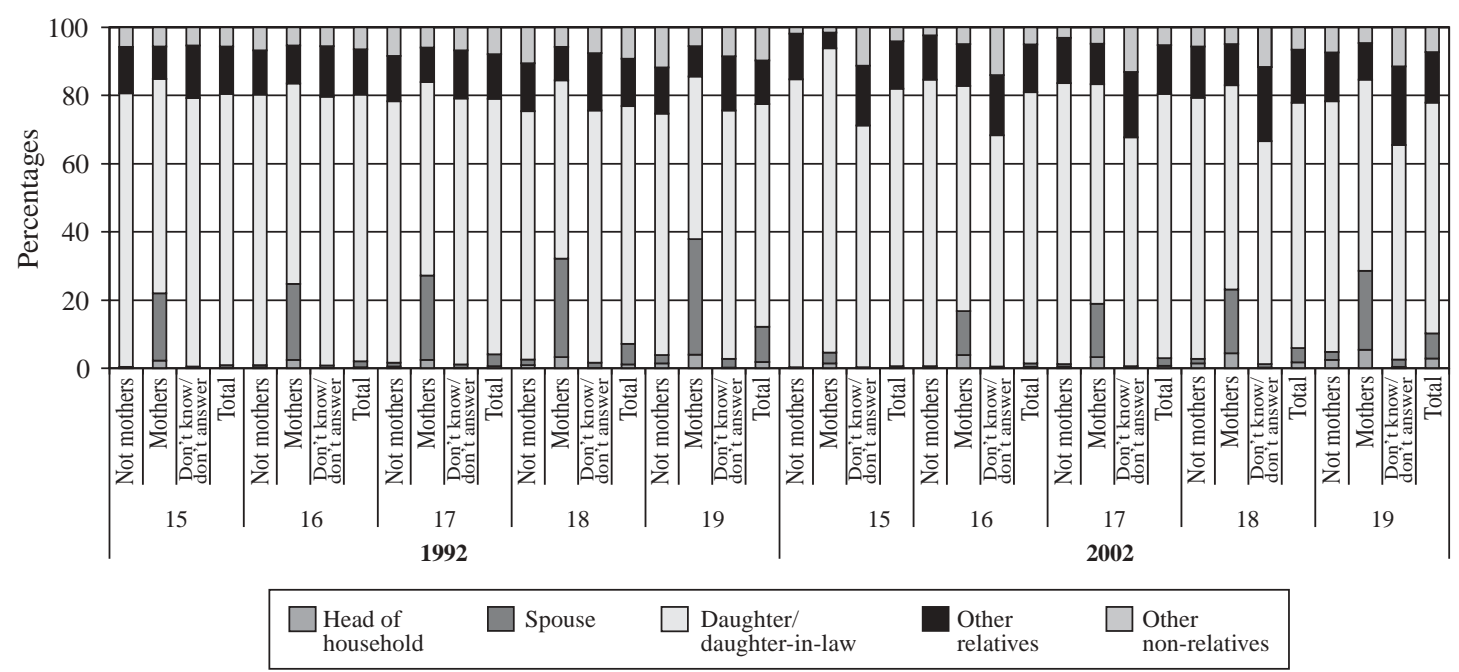

Source: Special processing of census micro-data bases.

FIGURE 7

Chile, girls between 15 and 19 years of age: Relative distribution of economic activity, by maternity status, 1992 and 2002

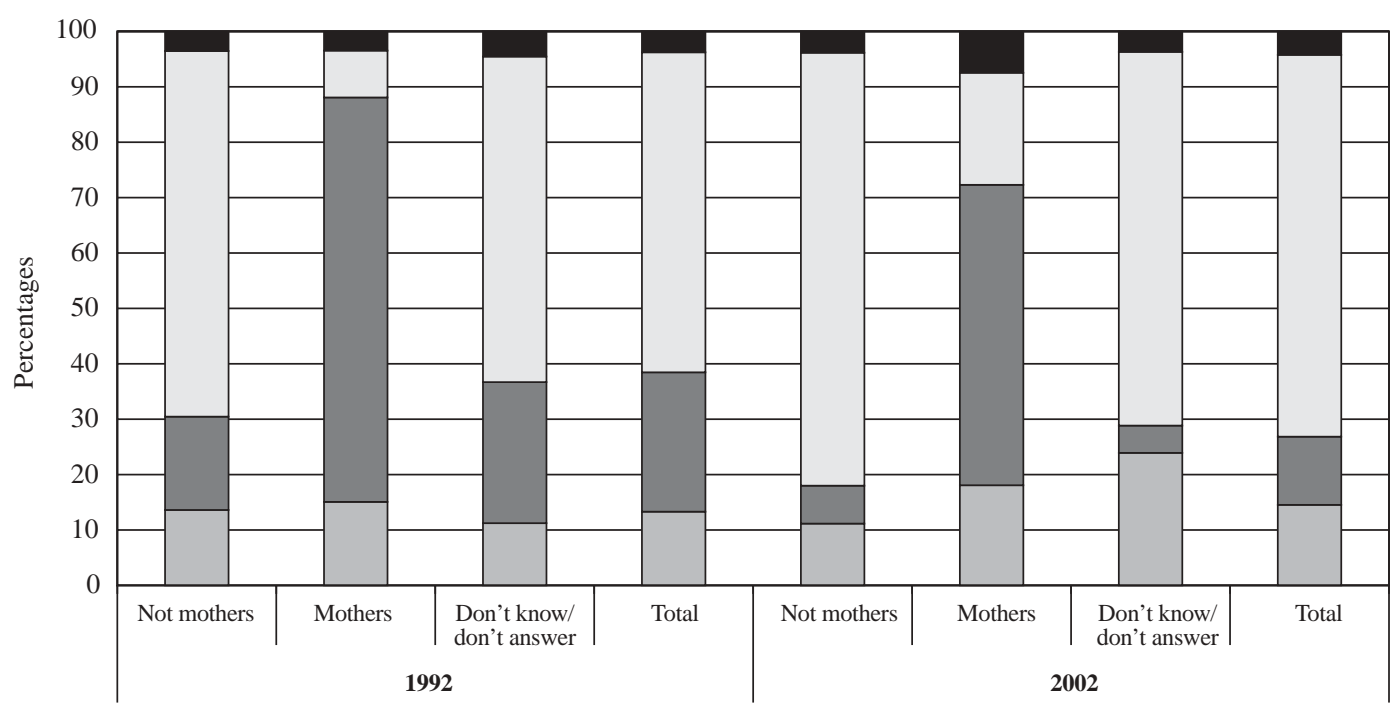

Maternity status and years

$\square$ Economically active $\square$ Staying at home $\square$ Studying $\square$ Other situation

Source: Special processing of census micro-data bases. 
process only extends to the end of secondary education, i.e., up to 17 or 18 years of age. Consequently, in the 15 to 19 age group there are different situations as regards the educational path completed. Figure 8 shows this information and presents some important findings. It confirms the pattern which distinguishes between adolescent mothers and : the former have a much greater likelihood of dropping out of the school system and devoting themselves solely to housework. ${ }^{11}$ According to the 2002 census, $85 \%$ of girls aged 17 who have not had children are studying, whereas among girls of that age who have children the proportion is only $30 \%$. It may be noted that the gap between the two groups is due to the fact that 17 year old mothers are ten times more likely to be engaged solely in housework than girls of the same age who are not mothers, and they are only twice as likely to be economically active. Thus, there is no doubt that adolescent maternity tends to cause girls to tackle the problem of raising their children by devoting themselves solely to housework rather than working, even though, in principle, the support of their families would make possible a redistribution of responsibilities which would give adolescent mothers time to take a job. Indeed, when a comparison is made between mothers and aged 19 - an age when most girls are no longer studying - the former still have a higher probability of not being economically active (figure 8 ).

FIGURE 8

Chile, girls between 15 and 19 years of age: Relative distribution of economic situation, by simple age and maternity status, 1992 and 2002

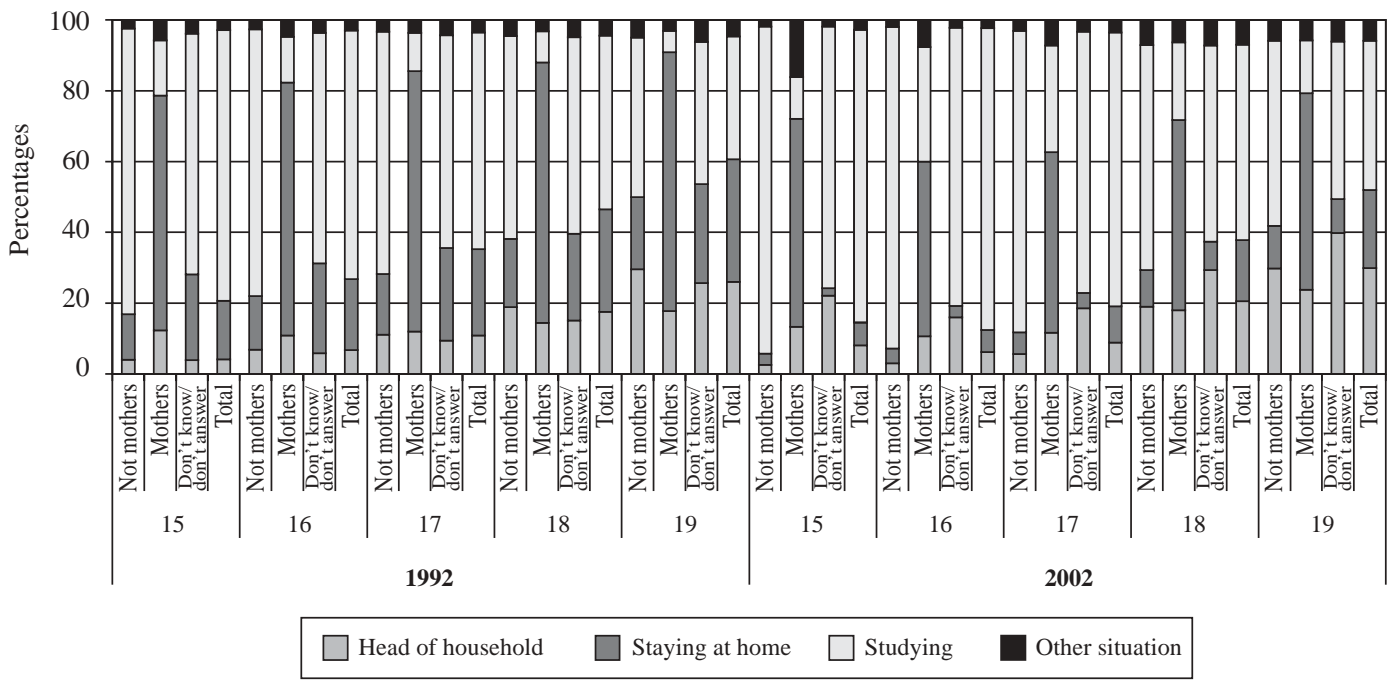

Source: Special processing of census micro-data bases.

\footnotetext{
${ }^{11}$ The three censuses may present problems as regards the status of student. It is not possible to use the direct question on school attendance, because this question was not included in the 1992 and 2002 censuses. The question on the kind of activity carried out was therefore used, because this question figured in all three censuses and included the status of "student" among the possible answers. According to the census enumerators' manuals, the information collected in this respect is comparable, because all three censuses register the main activity of the persons enumerated in the week
}

before the census. The drafting and possible alternative answers in the 1992 census are different from those of the 1982 and 2002 censuses, however. Thus, in the 1992 census the question does not make it clear that it is about the "main activity", and moreover the possible answer refers to "studying but not working". The practical consequences of these differences are relatively predictable (a proportion of students who are classified as working, because they worked during part of the week, thus increasing the numbers of dropouts) but impossible to estimate accurately. 


\section{Adolescent maternity, school career and incidence of dropping out: areas of light and shadow}

The figures presented above clearly suggest that early maternity is not very compatible with school attendance. The data in figure 9 confirm the previous findings, because they show that, systematically, adolescents who have had children are much more likely to be outside the school system: in 2002, only one out of every five adolescent mothers still attended school, whereas among those who had not had children, the proportion was four out of every five. This is particularly important in the case of girls of 16 and 17 , because at that age they should be completing the last two grades of secondary education, and the fact that they are not studying suggests that they have not reached the levels of compulsory education laid down in the law and considered to be minimum levels by present-day society and the labour market. In this age group ${ }^{12}$ maternity is associated with a probability of being outside the school system which is five times greater, and indeed, only $21 \%$ of mothers in this age group are still studying (figure 9 ).

Nevertheless, the results shown in figure 9 provide important information on the evolution of the status of

FIGURE 9

Chile, girls between 15 and 19 years of age who no longer study, by simple age and maternity status, 1982, 1992 and 2002

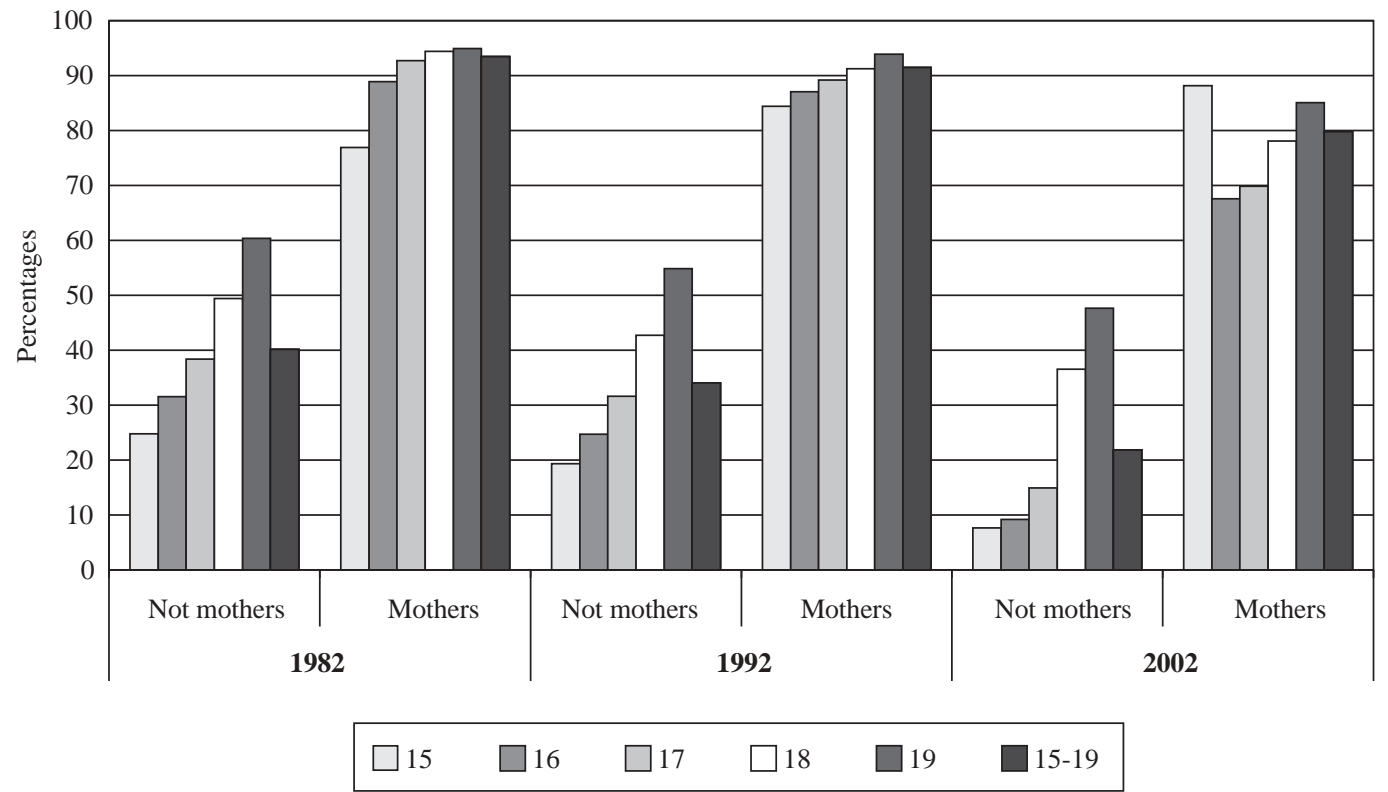

Source: Special processing of census micro-data bases.

12 The ages of 16 and 17 were selected because the behaviour of 15
year old mothers is anomalous, while at the age of 18 the girls in
question should normally have completed their secondary education and ceased to study, without being dropouts. This is clear because of the jump registered in the 2002 census, between the age of 17 and 18 , in the proportion of who no longer study (figure 9). 
student among adolescent girls, the sustained increase for both mothers and nulliparous girls being particularly noteworthy. Thus, for nulliparous girls between 15 and 19, the probability of not being a student went down from $40 \%$ in 1982 to nearly $20 \%$ in 2002. In 1982, in contrast, the incompatibility between being a mother and continuing to study was almost total, with less than $10 \%$ of adolescent mothers continuing their studies. In 2002, however, the corresponding figure was slightly over $20 \%$, and in the age groups where girls should normally have completed the 12 years of compulsory education, that likelihood was over $30 \%$ (figure 9).

Although it is strong, the above evidence is not in itself sufficient to conclude that early maternity is the reason why girls cease to study. There is much discussion on this possible relationship, because there are specialized studies in the region which suggest that in most cases girls drop out before they become pregnant. This discussion is in full progress in Chile, although the evidence available for contrasting the two positions empirically is only weak (Molina, Ferrada and others, 2004). Thus, some recent studies have arrived at controversial findings on the basis of samples which are not representative of adolescent boys and girls (Paz Ciudadana, Adimark and others, 2002), while other studies based on small samples give estimates that vary considerable (Molina, Ferrada and others, 2004). A more robust finding is that of the national economic and social profile survey (CASEN) carried out in 2000 , according to which not more than $20 \%$ of female dropouts were due to pregnancy or maternity (www.mideplan.cl/sitio/Sitio/estudios/documentos/ desercion19.pdf). This finding is corroborated by the Third Youth Survey, in which only $10 \%$ of young people who no longer studied declared that the reason was maternity or pregnancy. ${ }^{13}$

The census does not ask about the date of dropping out, or about whether the girl in question was pregnant or had given birth when she dropped out. By using the notion of the educational path as an analytical and operational tool, however, it is possible to go more deeply into this matter. In view of the tentative nature of this analysis and its contribution in terms of policy, only the results obtained with the 2002 census will be given. The notion of the educational path has been used

\footnotetext{
13 Strictly speaking, these data do not refer to dropping out from school, because they include young people who are no longer studying because they have completed their secondary education (www.injuv.gob.cl/cedoc_archivos/estudios/Tercera_encuesta.pdf).
}

in previous studies (Rodríguez, 2004) in order to gain a first approximation to the relation between dropping out and pregnancy. This notion is defined according to a simple algorithm which links the age of the person in question and the grade reached, on the understanding that there is a "normal" path in line with which it may be expected that at a given age the person will have reached a certain school grade. In order to facilitate the calculations, the age of 17 was used, and only girls with known maternity status were taken into account. Three categories of educational path are defined: seriously behind (less than eight years' schooling), moderately behind (eight or nine years' schooling) and normal (ten or more years' schooling). ${ }^{14}$

A first result is given in table 6,which, taking advantage of one of the strong points of the census, also includes absolute figures. As might be expected, the educational profile differs significantly between mothers and non-mothers, to such a point that the educational category of "seriously behind" predominates among the former, whereas it is registered only to a marginal extent among non-mothers. This latter finding contributes, although only indirectly, to the discussion on the order in time of the relation between pregnancy and dropping out. Thus, if a girl has not managed to complete her basic education by the age of 17 , there is a high probability that she is a dropout; ${ }^{15}$ furthermore, in view of her age when the census was taken and the grade reached, it may be estimated that on average she dropped out of the school system between three and four years before the census, that is to say, when she was between 13 and 14. Moreover, the great majority of 17 year old mothers have children under two years of age: that is to say, they were mothers after completing the age of 15 . It may be deduced from the foregoing that it is very likely that it is a question of dropping out before becoming pregnant. In the case of the "moderately behind" category, it is difficult to arrive at a tentative conclusion on the order of events. In the case of the "normal" category, in contrast, there

\footnotetext{
${ }^{14}$ The years of schooling is a variable constructed on the basis of two questions which are systematically repeated in the three censuses used in this study: the last grade reached, and the educational level attained. Thus, a value of 12 corresponds to a person who has completed the fourth year of secondary education and who may have finished his or her education at that point or may be continuing to study in the first year of the tertiary level (university or technical college) or the so-called "fifth year" of technical or professional secondary educational establishments.

15 Indeed, the census data themselves confirm this hypothesis: in 2002 only 392 of 5,049 mothers aged 17 with a "seriously behind" educational path were still studying.
} 
TABLE 6

Chile: Girls aged 17, with known maternity status, ${ }^{a}$

by educational path and maternity status, 2002

(Absolute and relative figures)

\begin{tabular}{|c|c|c|c|c|c|c|}
\hline \multirow[t]{2}{*}{ Educational path } & \multicolumn{3}{|c|}{ Number } & \multicolumn{3}{|c|}{ Relative structure (\%) } \\
\hline & Non-mothers & Mothers & Total & Non-mothers & Mothers & Total \\
\hline Seriously behind & 7919 & 5049 & 12968 & 9.4 & 41.4 & 13.5 \\
\hline Moderately behind & 18966 & 4029 & 22995 & 22.6 & 33.0 & 23.9 \\
\hline Normal & 57160 & 3119 & 60279 & 68.0 & 25.6 & 62.6 \\
\hline Total & 84045 & 12197 & 96242 & 100.0 & 100.0 & 100.0 \\
\hline
\end{tabular}

Source: Special processing of census micro-data bases.

a Excluding girls of unknown maternity status.

FIGURE 10

Chile: Girls aged 17, with known maternity status, by probability of still studying, according to educational path and maternity status, 2002

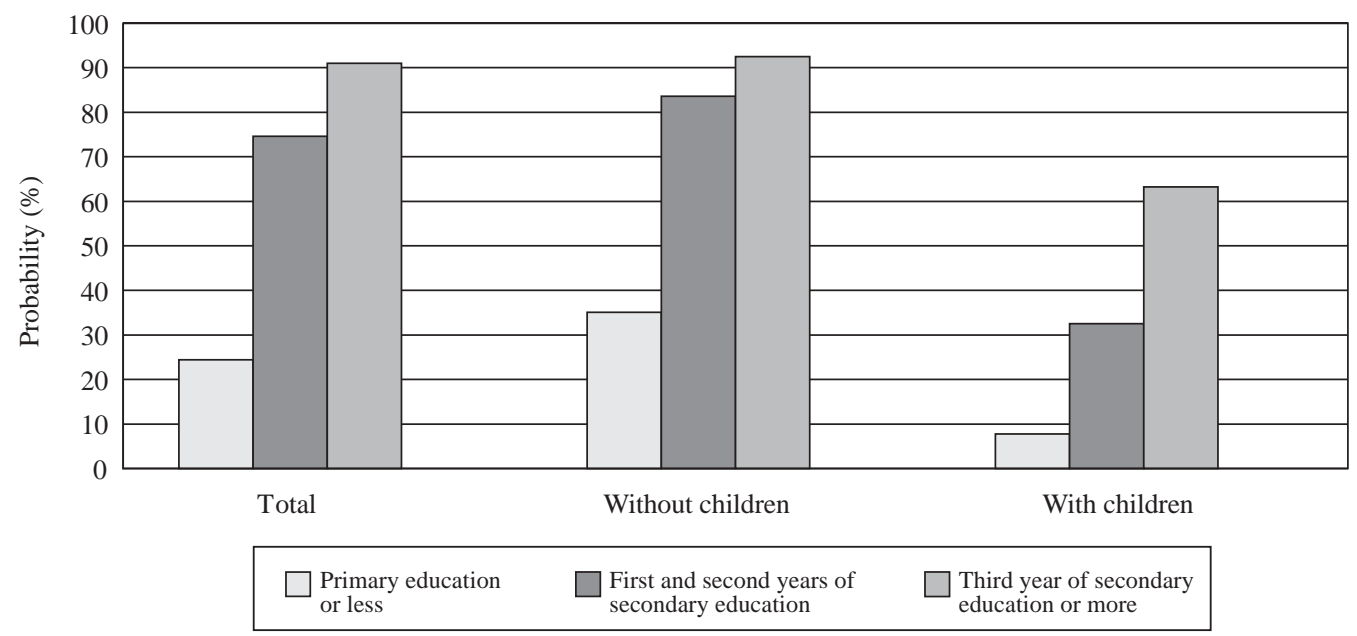

Source: Special processing of census micro-data bases.

is a high possibility that dropping out (which affects only $40 \%$ of adolescent mothers of that age and educational path) will have been due to pregnancy. In short, two tentative conclusions may be drawn: i) the case of dropping out and later pregnancy seems more frequent than the opposite case; ii) a "normal" educational path considerably increases the probability of staying in school after pregnancy. This is confirmed by figure 10 , which shows that in the "seriously behind" category dropping out takes place almost independently of whether the girl is a mother or not, while among mothers of 17 in the "normal" category the likelihood of staying in school is twice that of girls in the "moderately behind" category, and seven times higher than that of those who are seriously behind (see figure 10).

Finally, figure 11 completes the picture on the relation between educational path, type of activity, and adolescent maternity: among girls who are seriously behind educationally, maternity does not predispose them to greater participation in the labour market but leads them basically to carry out housework, probably in tasks connected with bringing up their children. This latter finding does not coincide with previous studies, such as that of Buvinic (1998), and reveals the cumulus of disadvantages that affect poor girls, for whom maternity coincides both with dropping out of school and remaining outside the labour market. 
FIGURE 11

Chile: Main activity of girls aged 17 , by educational path and maternity status, 2002

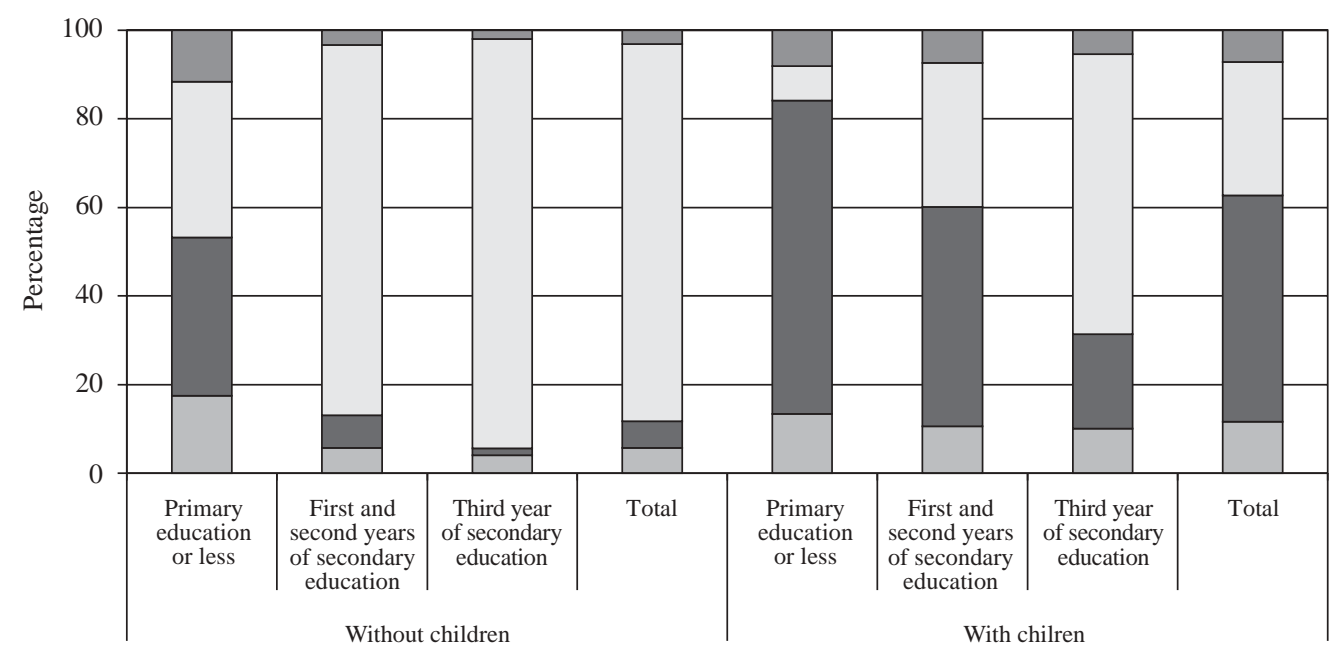

$\square$ Economically active $\square$ Housework $\square$ Studying $\square$ Other

Source: Special processing of census micro-data bases.

FIGURE 12

Chile: Girls aged 17, by main activity, according to educational path and maternity status, $2002^{a}$

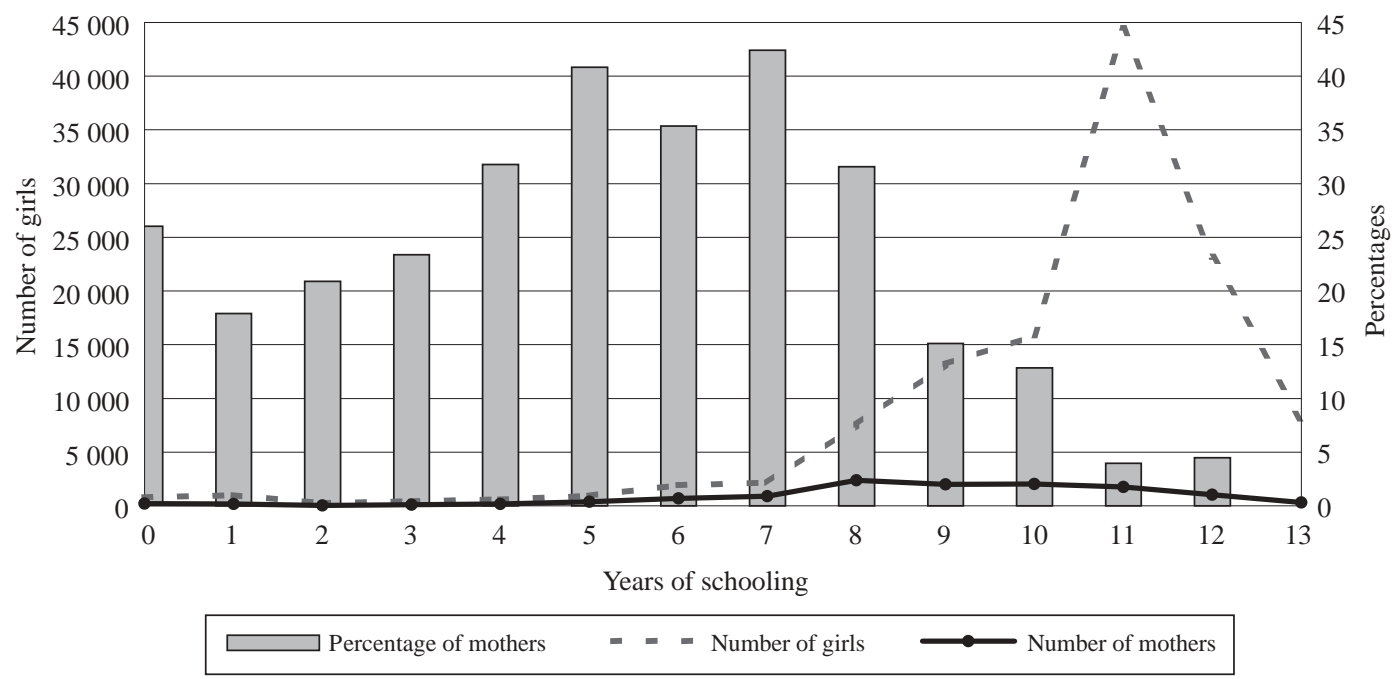

Source: Special processing of census micro-data bases.

a The probability takes account of all the girls in the age group, i.e., it imputes zero children to those who did not answer the question on the number of children born alive. The trends remain the same even if only the girls who answered are taken into account. 
Two important results should be mentioned here: i) whereas the majority of 17 year old girls have already completed the third year of the secondary cycle and are probably studying in the fourth year or even higher levels, $57 \%$ of mothers ${ }^{16}$ have not completed the second year, the modal frequency being the eighth year of primary education; that is to say, while adolescent mothers have less schooling than the average, they are far from being uneducated or poorly educated; ii) the probability of having been a mother at the age of 17 is closely linked with the level of schooling of girls, but this relation is not linear, since three groups must be distinguished: those who have not completed the fourth year of primary education (a probability of $26 \%$ or less); those who have completed between the fourth and eighth years of primary education (a probability of $30 \%$, rising to $42.4 \%$ for those who completed only up to the seventh year of primary education; and those who have completed the first year of secondary education (nine years' schooling) or have completed higher levels of education, for whom the probability is $15 \%$ or less, sinking to less than $5 \%$ for those who have completed the third year of secondary education or have even higher levels of schooling (see figure 12). It may thus be concluded that, in spite of the persistent and undeniable association between greater education and a lower probability of being an adolescent mother, there are signs that the completion of more years of schooling does not have a continuous protective effect against early maternity, since girls who have completed between four and eight years' schooling by the age of 17 are more exposed to the risk of being adolescent mothers than those with less schooling. In other words, it is necessary to have passed a certain threshold of accumulation of schooling in order to the protection against pregnancy to become active. This latter finding should be interpreted with caution, however, because there are very few girls with less than four years' schooling, and there are indications that some of them correspond to special cases of cutting short of the educational path simultaneously linked with a smaller probability of becoming a mother (disabling illnesses and/or accidents, severe learning retardation, etc.).

\section{VI}

\section{Poverty and adolescent maternity: continuity and change of a historical relationship}

The probability of being a mother at an early age is not distributed randomly among the socio-economic groups, since it is higher among the poor, excluded or socially disadvantaged groups. Using as a socioeconomic stratification variable a simple equipment index which makes it possible to segment households into specific socio-economic terciles for urban and rural areas, it is found that in these situations girls in the bottom tercile have a much greater likelihood of having had children at all the ages covered by the term "adolescence". Approximately 50\% of the girls in the bottom socio-economic tercile in rural areas had their first child before they were 20 , while this situation only affected less than $15 \%$ of girls in the top urban tercile. It should be noted that the gaps are only moderate

\footnotetext{
${ }^{16}$ Exactly $57 \%$ of them have only completed the first year of secondary education (a value of 9 for the schooling variable) or even less. This information is given because figure 11 does not make this clear visually.
}

because of the use of terciles based on a socioeconomic equipment index as socio-economic categories. If the distinction had been the classic one between indigent, poor and non-poor persons (ECLAC, 1998) the disparity would have been greater.

It should also be noted that this difference in terms of adolescent fertility is observed even though in Chile there has tended to be convergence among the socioeconomic groups in this respect. According to indirect estimates made with the $\mathrm{P} / \mathrm{F}$ procedure (Brass, 2002), women without education had a total fertility rate (TFR) of 2.5 children; those with between 1 and 8 years' schooling had a TFR of 2.8 children; those with between 9 and 12 years' schooling had a TFR of 2.5 children, and finally, women with 13 or more years' schooling had a TFR of 1.8 children. ${ }^{17}$ Comparison of figures 13 and 14 ,

\footnotetext{
17 These differences were much more marked in 1982, when the respective TFRs were 4.1, 3.7, 2.5 and 2.1 (calculations based on census micro-data, using Brass's indirect $\mathrm{P} / \mathrm{F}$ method of estimation).
} 
FIGURE 13

Chile: Girls between 15 and 19 years of age, by simple age and probability of having had one or more children, according to socio-economic tercile and area of residence, 2002

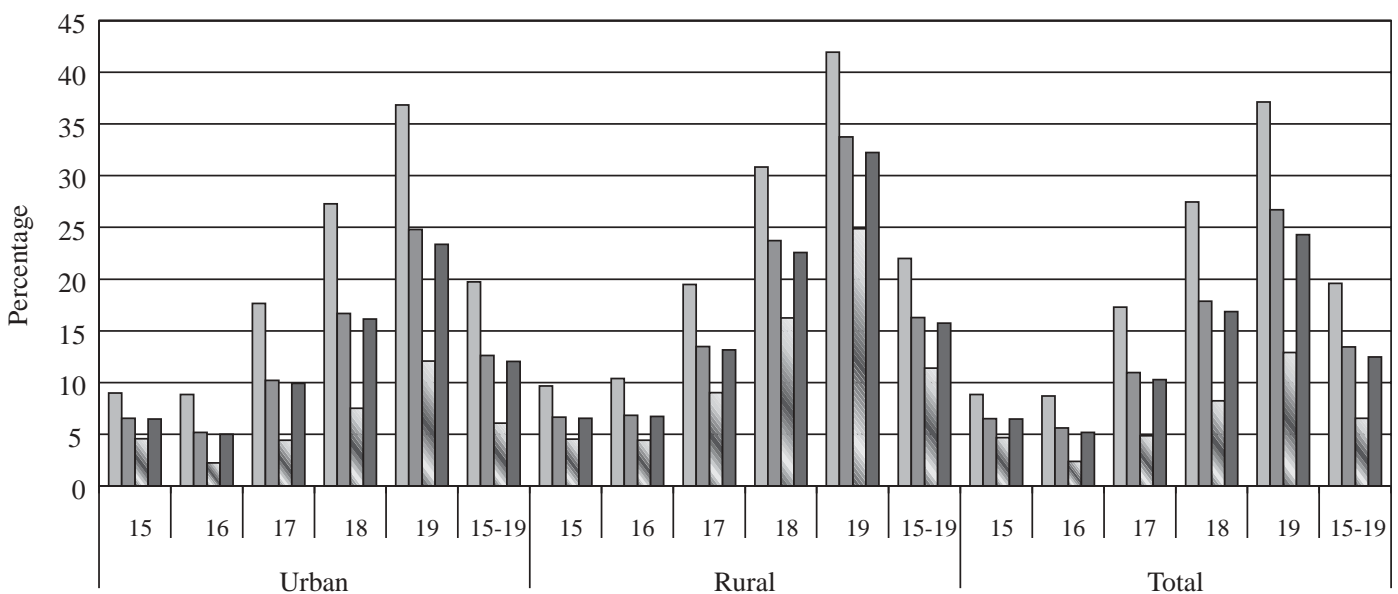

$\square$ Bottom $\square$ Middle $\square$ Top $\square$ Total

Source: Special processing of census micro-data bases.

FIGURE 14

Chile: Girls between 15 and 19 years of age, by simple age and probability of having had one or more children, according to socio-economic tercile and area of residence, 1992

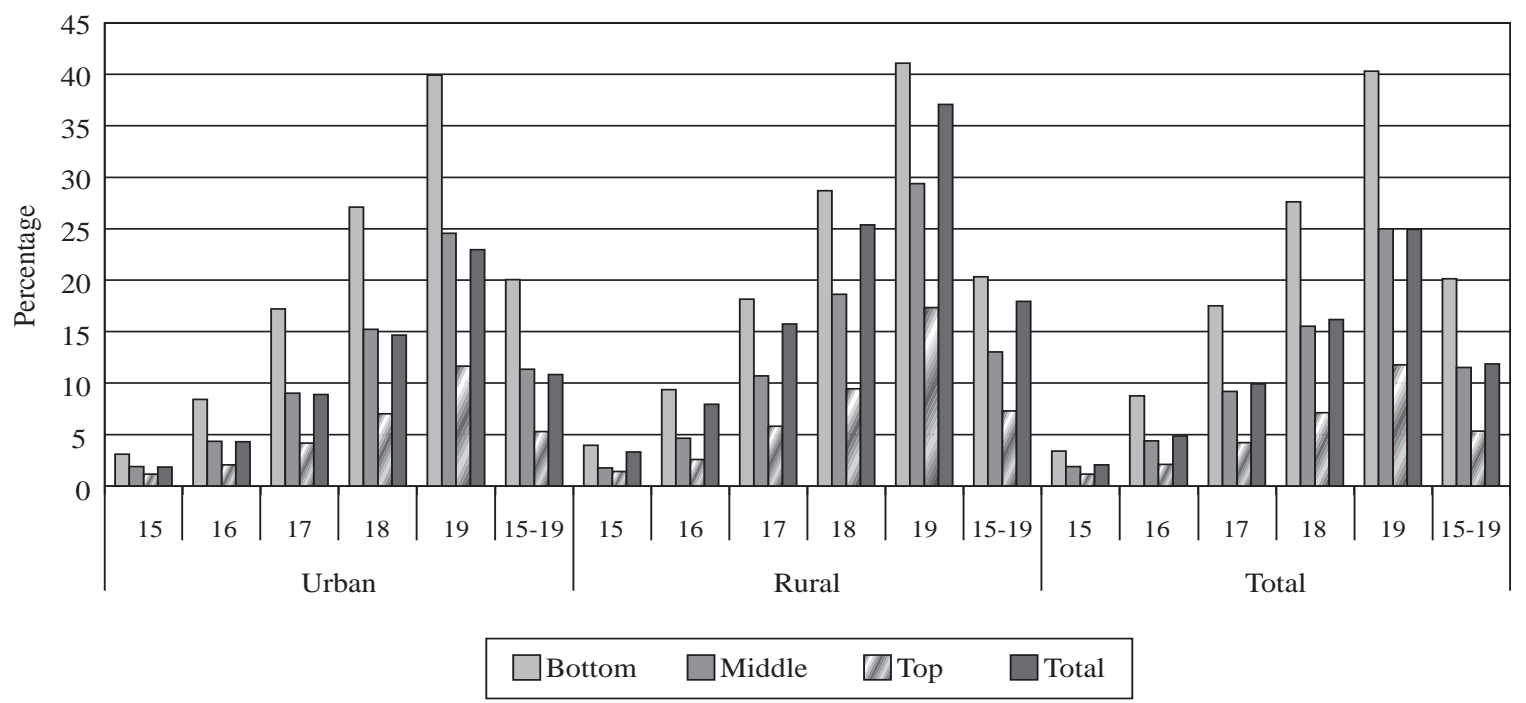

Source: Special processing of census micro-data bases.

in contrast, suggests that the differences between social groups in terms of adolescent maternity remained practically unchanged between 1992 and 2002; if we consider only the group of 19 year old women, for which the figure comes closest to the probability of having children during adolescence, there was a slight decline 
in the bottom tercile (from $40 \%$ in 1992 to $37 \%$ in 2002), a slight increase in the middle tercile (from $25 \%$ in 1992 to $27 \%$ in 2002), and a slight rise in the top tercile also (from 11\% in 1992 to $13 \%$ in 2002). In short, while the disparities in intensity of reproduction between socio-economic groups have lessened, this has not occurred in terms of the age of first pregnancy, which continues to be much earlier among poor girls.

\section{VII}

\section{On the determinants of adolescent pregnancy: a first approximation}

The factors influencing the probability of being an adolescent mother have undoubted socio-economic dimensions: poverty, exclusion, and lack of options. These interact with other factors to configure both the specific forms of reproductive conduct of each adolescent and the aggregate trends formed by those individual forms of behaviour. Among these other factors are:

a) psychological factors, that is to say, personality traits to which surveys and censuses devote little or no attention, so that there is a serious lack of information on their large-scale action;

b) individual factors, i.e., personal attributes acquired in the socialization process which affect a person's conduct, such as religion;

c) family factors, which concern the domestic environment in which boys and girls live and which influence them through the models of conduct they provide, the limits they lay down, the rules they provide, and the forms of control they exercise;

d) cultural factors, which have various aspects: i) the traditions which affect adolescent maternity because they promote and/or accept early unions; ii) marginality, which may be directly linked with the exclusion and poverty already mentioned and which tends to make adolescent reproduction more frequent in a context of little supervision (parental, institutional or in health matters), and the lack of options other than that of early maternity; and iii) sexual tolerance, specifically in terms of pre-marital sexual initiation (although not necessarily at an early age), which, if not associated with greater tolerance of and access to contraceptive means (truncated sexual modernity), can favour adolescent maternity;

e) political and institutional factors, especially programmes, organizations, actions, laws and regulatory frameworks which affect adolescents and define the forms of conduct permitted for them, and

f) the mass media, whose messages about eroticism, affection and sexuality are a powerful influence on boys and girls.

Disentangling the way these factors affect individual forms of behaviour is a task which is still outstanding and is outside the scope of this article. At all events, these are ultimate determinants, since, as laid down in the "framework for intermediate fertility variables" (Bay, del Popolo and Ferrando, 2003; Bongaarts, 1978), there is a set of "proximate fertility determinants" which are those that directly define the probability of having a child and the aggregate fertility trends. These proximate determinants are connected with biological conditions (fertile stage of life, total or transitory sterility, as usually occurs during breastfeeding, propensity for multiple pregnancies, etc.); with sexual behaviour (initiation, regularity, total or temporary abstinence for cultural reasons, etc.), which has historically been closely linked with patterns or formation and dissolution of unions; with contraceptive practices (initiation, regularity, efficiency and type of method), and with the frequency of spontaneous or induced abortion.

Adolescent fertility is directly affected by five proximate determinants: i) the age of menarche, ii) the indices of infertility, iii) the patterns of sexual initiation and activity, iv) the patterns of contraceptive use, and v) the indices of spontaneous or induced abortion. The first two are generally not taken into consideration because they do not help much to explain crosssectional (between socio-economic groups) or longitudinal (evolution over time) differences in fertility. The third determinant is usually replaced by patterns of union, on the assumption that this information is easier to obtain. The last two 
determinants are of crucial importance, mainly because they tend to prevail over the rest in present-day societies. In other words, when efficient contraceptive use is high, regular and begins at an early age, most couples will have the number of children they want. Consequently, the direct causes why adolescent fertility resists going down in Chile should be sought in the evolution of these proximate determinants. Unfortunately, there is no single, reliable and suitable source of information for obtaining these data; indeed, in the case of some of them (such as induced abortion) there are not even any reliable estimates, because induced abortion, for example, is a criminal offence under present Chilean law in any circumstances.

Nevertheless, there are some indications that allow the situation to be clarified a little more. Firstly, there is no reason why Chile should be an exception to the long-standing trend towards earlier menarche and an increase in the biological reproductive capacity of adolescents (Silber and Castells, 2003, p.24), although, because of the small number of births before the mother is 15 , this tendency can hardly explain the evolution of adolescent maternity. Secondly, the pattern of union shows signs of becoming increasingly late, which likewise reduces its importance as a factor explaining adolescent fertility trends, because this increasing lateness should cause adolescent fertility to be going down. Thirdly, the few nationwide studies on sexual and contraceptive patterns suggest that: i) over the last 60 years the age of sexual initiation has remained relatively stable, with a median for women going down from 21.3 years of age (for the cohort born between 1944 and 1948) to 18 years of age (for the cohort born between 1979 and 1980), although the youngest generations seem to be initiating their sexual life earlier (CONASIDA, 2000, pp.154-158; INJUV (undated), p.13); ii) men typically declare an earlier age of sexual initiation, although the differences between the sexes in this respect have tended to go down (INJUV (undated), pp.16-17); iii) there has been a considerable increase in the proportion of girls and boys who take contraceptive precautions in their sexual initiation: for example, in the year 2000 one out of every four women with sexual experience between 18 and 24 years of age had done so, compared with only six out of every hundred women aged between 45 and 69 in the same year; iv) in spite of this increase, contraceptive use among adolescents continues to be low, so that most adolescent girls are exposed to the risk of becoming pregnant.

In short, the earlier age of sexual initiation seems to offset the higher levels of contraceptive use in the

FIGURE 15

Ibero-America: Percentage of girls who used modern contraceptives in their first intercourse, ${ }^{a}$ various years between 1991 and 2000

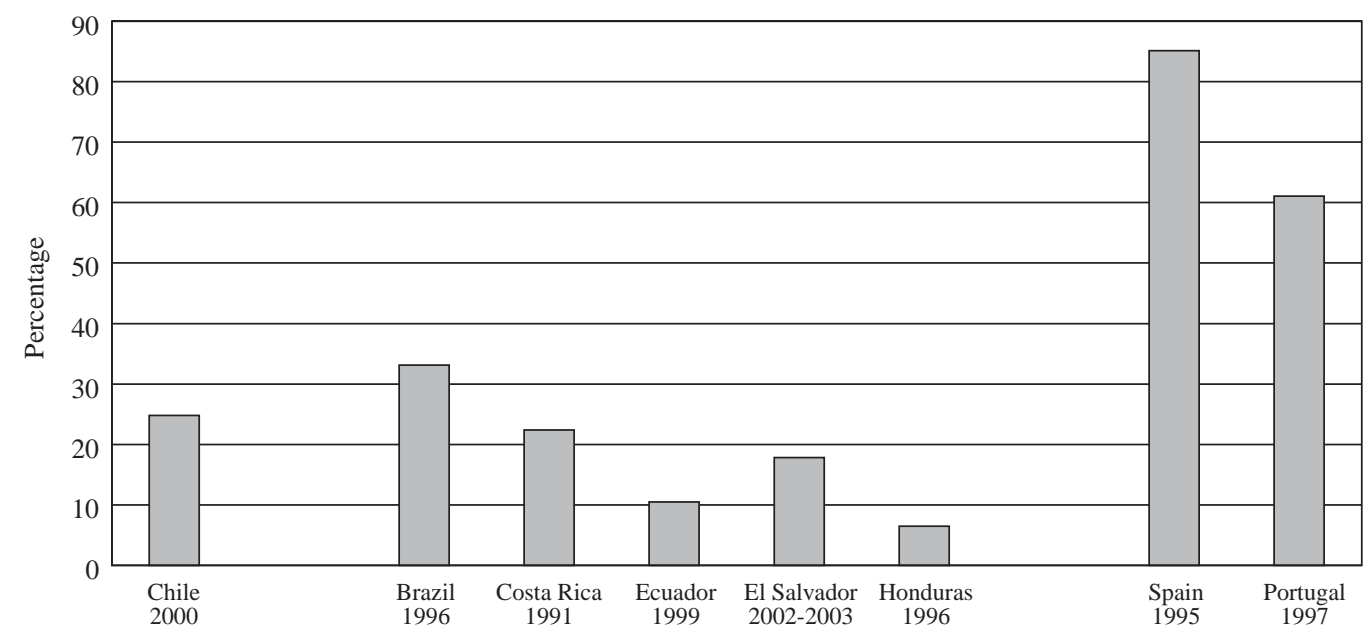

Source: Spain and Portugal: United Nations, Fertility and Family Surveys (various years). Latin American countries (except Chile and El Salvador): CEPEP/USAID/CDC (1999, p.72, table 7.13). El Salvador: ADS/CDC (2003, p.200, table 9.12). Chile: CONASIDA (2000, p.158).

a In Spain, the figures refer to the 18-19 age group, in Portugal to the 20-24 group, in Chile to the 18-24 group, and in the rest of the Latin American countries to the 15-24 age group. 
first union. Moreover, this figure does not make it possible to estimate if contraception is practiced regularly once sexual life has been initiated, or if contraception is practiced carefully and efficiently. Recent data indicate that nearly $35 \%$ of persons between 15 and 19 years of age in 2003 did not use contraceptive protection in their last sexual intercourse and that $6 \%$ used unsafe forms such as coitus interruptus (INJUV (undated), pp.16-17). This tension between earlier sexual initiation and a pattern of contraception use which is not spreading as strongly or being used as regularly by adolescents (figure 15) is the reason for the persistent levels of adolescent maternity described in this study.

Unlike what happens with respect to general reproduction trends in adolescence, patterns of union do appear to have a relation with the economic and social disparities of adolescent maternity. Thus, the census evidence suggests that historically girls from the lower strata have had a tendency to enter into a union (marry or cohabit) earlier, which favours earlier reproduction (ECLAC/OIJ, 2003). The high and growing frequency of maternity outside a stable union, however, suggests that the main factor differentiating between the socio-economic groups lies in their sexual and contraceptive conduct. Although the empirical evidence in this respect is not systematic, the survey carried out by CONASIDA in 2000 shows that sexual initiation takes place earlier among girls who have less education and/or belong to the lower strata; thus, the upper middle socio-economic group has a median initiation age of 19.4 years compared with 17.9 years for the low socio-economic group (CONASIDA, 2000, p.161). Unfortunately, the publication in question does not offer information on social inequalities as regards contraceptive use and still less as regards the use made of abortion, but in view of the characteristics of contraceptive supply in Chile it is probable that contraceptive use among sexually active adolescents is lower in the lower socio-economic groups.

\section{VIII}

\section{Final analysis: policy inputs}

In view of all the foregoing —adolescent maternity which resists going down; the increase in adolescent maternity among single girls; the much higher probability that adolescent mothers will be outside the school system and engaged basically in housework; the transfer to their parents of responsibility for bringing up the children of these girls, and the much higher probability that poor adolescent girls will be mothers before they are 20- there can be no doubt that adolescent pregnancy and maternity should be among the highest-priority items on the social agenda and should be the subject of coordinated public programmes. Indeed, the persistence of a high level of adolescent fertility may even erode the benefits of the decline in total fertility. In this respect, in policy formulation it is important to note that adolescent reproduction does not display the usual patterns of relation with the intermediate variables. This fact confirms the appeal made in the Programme of Action of the International Conference on Population and Development for governments, in collaboration with non-governmental organizations, to "meet the special needs of adolescents and to establish appropriate programmes to respond to those needs" (http:// www.unfpa.org/icpd/icpd_poa.htm\#ch7e) and calls for a special effort to draft and implement measures that recognize the special features of adolescents of both sexes, especially as regards their conduct in terms of sexual behaviour at the level of the couple, and practices of self-care and protection.

A second important item to be taken into account in policy formulation concerns the distinction between at least two forms of reproductive behaviour in adolescence. The more traditional form has cultural roots which are difficult to remove, but measures designed to postpone unions and, above all, to expand the coverage of sexual and reproductive health services among girls who have established a union (assuming that procreation in these contexts takes place within unions) can give results in terms of both the age of initiation and the intensity of fertility. The form of reproductive behaviour connected with what has been called "truncated modernity" in this study, for its part, demands rapid and broad-ranging action. The most direct forms of this action concern education and the encouragement of responsible forms of conduct, both 
to postpone the age of sexual initiation and to take contraceptive measures from the very beginning. In order to achieve this latter objective, education alone is not enough: it is necessary to bring closer to adolescents services in the areas of counselling, specialized support, and distribution of contraceptives (and training in their regular and proper use).

A third contribution which the present study seeks to make to policy formulation is the updating of the role of the school system and education in general with regard to reproduction during adolescence. Thus, there is evidence of a certain loss of influence of education as a factor protecting against adolescent maternity. At the aggregate level, this is linked with the lack of a direct connection between adolescent maternity (which has remained constant or risen slightly over the last 20 years) and the average level of schooling of adolescent girls and boys (which rose considerably over the same period). At the individual level, this means that those with the greatest probability of being adolescent mothers are not the girls with the least education, but those with between 5 and 7 years' schooling. Nevertheless, the main policy conclusion of the study is that a "normal" educational path in which the secondary cycle is completed at the age of 17 or 18 acts as powerful - albeit not infallible - protection against adolescent maternity, and it also considerably increases the likelihood that a girl will continue studying after giving birth. In short, avoiding premature abandonment of school becomes a multiple policy objective.

The contributions referred to above highlight at least six spheres of action. The first is the public sphere, and has to do with the general administrative and legal provisions which limit the access of adolescents to knowledge and proper use of contraceptive means. Comparative experience, especially the case of Western Europe, suggests that the main means for achieving low levels of reproduction during adolescence is access to contraceptives from the very beginning of sexual life and training in their regular, responsible and efficient use. It is paradoxical, in this respect, that while many countries of the region tend to lower the minimum age of responsibility, for example in penal matters, they maintain higher minimum age limits for the purchase or provision of contraceptive means. The experience of Latin America represents a warning against the shortcomings of measures that provide purely formal expansion of access to these means. In order for this expansion of access to give results, it must apply before adolescent boys and girls enter into their first union or sexual relationship - which runs counter to the practice of accepting adolescents in family planning programmes only if they have already established a union or had a child - and it must be accompanied by different kinds of measures to strengthen desirable practices, especially as regards responsible conduct in sexual matters.

The second sphere is that of cultural aspects, and is connected with the contrast between supposedly serious discourses aimed at boys and girls (by institutions and their elders) which elude or ignore the realities of adolescent sexuality, on the one hand, and the constant exposure of these young people to images, symbols and stimuli that encourage early sexual activity, on the other. Thus, in addition to the necessary normative protective that pubescent and adolescent young people need against the insinuations, pressures and aggressions of adults, especially in sexual matters, and the essential need to give them the capacity to take responsible decisions, it is also of crucial importance to update the images transmitted by official and family circles. The idea that unmarried adolescent boys and girls (the majority, as we have seen) should not be engaging in sexual activities and hence do not need to use contraceptive means is in open contradiction with reality and with the everyday world that young people live in, which is full of sexual symbols and allegories.

The third sphere is the sectoral sphere, especially that of the health sector, where there is still much reluctance to give adolescent boys and girls special treatment and try to come closer to them, so that many of them remain distant from such services. As already emphasized, in order to bring girls and boys closer to health services it is necessary to provide them with spaces where they receive some degree of special attention, even within integral programmes of health attention.

The fourth sphere is that of the school, which can provide a wide range of mechanisms to protect against adolescent maternity. So far, some of these mechanisms seem to be based on the mere fact of "being there" and occupying time in an activity which helps to put order in everyday life, disciplines conduct and concentrates efforts, thus adding a positive externality to programmes designed to keep young people in school until they complete the secondary cycle. Others are based on the possibilities provided by education in terms of knowledge and use of contraceptive precautions, management of natural impulses, and technical and affective training in matters 
of sexuality and reproduction. Others are associated with the expectations and horizons opened up by the accumulation of education, either for taking a job or for continuing to study at a higher level. While the school undoubtedly has a "protective" role with regard to adolescent pregnancy, however, the effects of this role should not be taken for granted. This space, like any other, makes possible interaction and sexual encounters between boys and girls and tends to promote lifestyles which are often more tolerant on sexual matters, so that consideration should be given to the provision of some kind of special training in informed and responsible sexuality; moreover, if secondary education loses some of its value as a factor of social mobility, this also weakens its capacity to act as a real alternative to adolescent pregnancy.

The last two spheres have to do with the more direct circle of adolescent boys and girls, namely, the family and the couple. The family has an enormous influence on the conduct of boys and girls and is the main channel for their preparation and training as responsible individuals. When families instruct and prepare their children properly, it is much more likely that the sexual conduct of the latter will be of a responsible nature. In some cases, this responsibility may lead them to put off their first sexual relationship, while in others it will lead them to take precautions to avoid unwanted pregnancies and health problems. It must be acknowledged, however, that in many cases there is little communication between the family and their adolescent children (because the family do not take an interest, because they hold principles that the adolescents do not share, or because they have an unrealistically idealized idea of their children's conduct), and in these circumstances, sooner or later, it is the adolescent who must take the decisions. Finally, with regard to the couple, the capacity to talk things over and share responsibilities is one of the most promising contexts for the promotion of responsible forms of sexual and reproductive conduct.

(Original: Spanish)
ADS/CDC (Asociación Demográfica Salvadoreña/Centers for Disease Control and Prevention) (2003): Encuesta Nacional de Salud Familiar: FESAL 2002/03, San Salvador.

Bay, G., F. del Popolo and D. Ferrando (2003): Determinantes próximos de la fecundidad: una aplicación a países latinoamericanos, "Población y desarrollo" series, No. 43, LC/ L.1953-P; LC/L.1953-P/Corr.1-P, Santiago, Chile. United Nations publication, Sales No. S.03.II.G.21.

Bongaarts, J. (1978): A framework for analyzing the proximate determinants of fertility, Population and Development Review, vol. 4, No. 1, New York, Population Council.

Buvinic, M. (1998): Costos de la maternidad adolescente en Barbados, Chile, Guatemala y México, technical report, No. WID-102, Washington, D.C., Inter-American Development Bank.

CEPEP/USAID/CDC (Paraguayan Centre for Population Studies/United States Agency for International Development/Centers for Disease Control and Prevention) (1999): Encuesta Nacional de Salud Materno Infantil, 1998 (ENSMI-98). Informe final, Asunción.

CONASIDA (Comisión Nacional del Sida) (2000): Estudio nacional de comportamiento sexual: primeros análisis. Chile 2000, Santiago, Chile, Ministry of Health.

Donoso, E., J. Becker and L. Villarroel (2003): Birth rates and reproductive risk in adolescents in Chile, 1990-1999, PanAmerican Journal of Public Health, vol. 14, No. 1, Washington, D.C., Pan-American Health Organization.

Dulanto, E. (2000): El adolescente, Mexico City, McGraw-Hill Interamericana

ECLAC (Economic Commission for Latin America and the Caribbean) (1998): Social Panorama of Latin America, 1997, LC/G.1982-P, Santiago, Chile. United Nations publication, Sales No. E.98.II.G.3.
ECLAC/CELADE (Economic Commission for Latin America and the Caribbean/Latin American and Caribbean Demographic Centre (CELADE) - ECLAC Population Division (2002): Vulnerabilidad sociodemográfica: viejos y nuevos riesgos para comunidades, hogares y personas, LC/G.2170(SES.29/16), Santiago, Chile.

(2004): La fecundidad en América Latina: ¿transición o revolución?, "Seminarios y conferencias" series, No. 36, LC/ L.2097-P, Santiago, Chile. United Nations publication, Sales No. S.04.II.G.34.

ECLAC/OIJ (Economic Commission for Latin America and the Caribbean/Ibero-American Youth Organization) (2003): Juventud e inclusión social en Iberoamérica, LC/R.2108, Santiago, Chile.

(2004): La juventud en Iberoamérica: tendencias y urgencias, LC/L.2180, Santiago, Chile.

Esping-Andersen, G. (1999): Social Foundation of Postindustrial Economies, Oxford, United Kingdom, Oxford University Press.

Flórez, C. and J. Núñez (2003): Teenage childbearing in Latin American countries, in S. Duryea, A. Cox and M. Ureta (eds.), Critical Decision at a Critical Age, Adolescents and Young Adults in Latin America, Washington, D.C., Inter-American Development Bank.

Gage, A. (1995): The Social Implications of Adolescent Fertility, document presented at the Conference on Demography and Poverty (Florence, Italy, 2-4 March 1995), International Union for the Scientific Study of Population.

Guzmán, J., R. Hakkert and others (2001): Diagnóstico sobre salud sexual y reproductiva de adolescentes en América Latina y el Caribe, Mexico City, United Nations Population Fund (UNFPA).

INE (National Institute of Statistics) (2000): Fecundidad juvenil, Enfoques estadísticos, No. 9, Santiago, Chile, in <www.sexualidadjoven.cl/estudios/enf_fecundidad.pdf>. (various years): Anuario de demografía, Santiago, Chile. 
INJUV (National Institute for Youth) (n/d): La eventualidad de la inclusión: jóvenes chilenos a comienzos del nuevo siglo. Principales resultados: Tercera Encuesta Nacional de Juventud, in (http://www.injuv.gob.cl/cedoc_archivos/estudios/ Tercera_encuesta.pdf).

IPAS (2001): Jóvenes en riesgo: los adolescentes y la salud sexual, Notas informativas, Chapel Hill, January, in (www.ipas.org).

Lete, I., J. de Pablo and others (2001): Embarazo en la adolescencia, in C. Buil, I. Lete and others (coords.), Manual de salud reproductiva en la adolescencia: aspectos básicos y clínicos, Madrid, Sociedad Española de Contracepción (http:// ns.ccp.ucr.ac.cr/bvp/pdf/manual/saludreproductiva/).

Menkes, C. and L. Suárez (2003): Sexualidad y embarazo adolescente en México, Papeles de población, No. 35, Mexico City, National Autonomous University of Mexico.

Molina, M., C. Ferrada and others (2004): Embarazo en la adolescencia y su relación con la deserción escolar, Revista médica de Chile, vol. 132, No. 1, Santiago, Chile, Sociedad Médica de Chile.

Molina, R., J. Sandoval and E. González (2003): Salud sexual y reproductiva en la adolescencia, Santiago, Chile, Mediterráneo.
United Nations (1983): Manual X. Indirect Techniques for Demographic Estimation, "Population Studies", No. 81, ST/ ESA/SER.A/81, New York. United Nations publication, Sales No. E.83.XIII.2.

Paz Ciudadana, Adimark and others (2002): Deserción escolar en Chile, Santiago, Chile.

Rodríguez, J. (2004): La fecundidad en América Latina y el Caribe: un riesgo en transición, in La fecundidad en América Latina: ¿transición o revolución?, "Seminarios y conferencias" series, No. 36, LC/L.2097-P, Santiago, Chile, Economic Commission for Latin America and the Caribbean (ECLAC). United Nations publication, Sales No. S.04.II.G.34.

SERNAM (National Women's Service) (2004): Mujeres chilenas. tendencias en la última década, Santiago, Chile, Departament of Studies and Statistics.

Silber, T. and P. Castells (2003): Guía práctica de la salud y psicología del adolescente, Barcelona, Planeta.

Singh, S. (2000): Diferencias según sexo en el momento de la primera relación sexual: datos de 14 países, Perspectivas internacionales en planificación familiar, special issue, Mexico City, National Public Health Institute. 